\title{
Photoaquation Mechanism of Hexacyanoferrate(II) ions: Ultrafast 2D UV and Transient Visible and IR Spectroscopies
}

\author{
Marco Reinhard ${ }^{1 \dagger}$, Gerald Auböck ${ }^{1 \ddagger}$, Nicholas A. Besley ${ }^{2}$, Ian P. Clark ${ }^{3}$, Gregory M. \\ Greetham $^{3}$, Magnus W. D. Hanson-Heine ${ }^{2}$, Raphael Horvath ${ }^{2}$, Thomas S. Murphy ${ }^{2}$, \\ Thomas J. Penfold ${ }^{4}$, Michael Towrie ${ }^{3}$, Michael W. George ${ }^{2,5}$ and Majed Chergui ${ }^{1}$ \\ ${ }^{1}$ Ecole polytechnique Fédérale de Lausanne, Laboratoire de spectroscopie ultrarapide, ISIC and Lausanne Centre for Ultrafast Science \\ (LACUS), FSB, Station 6, CH-1015 Lausanne, Switzerland \\ ${ }^{2}$ School of Chemistry, University of Nottingham, Nottingham NG7 2RD, United Kingdom \\ ${ }^{3}$ Central Laser Facility, Research Complex at Harwell Science and Technology Facilities Council, Rutherford Appleton Laboratory, \\ Harwell Oxford, Didcot, Oxfordshire OX11 0QX, United Kingdom \\ ${ }^{4}$ School of Chemistry, Newcastle University, Newcastle upon Tyne NE1 7RU, United Kingdom \\ ${ }^{5}$ Department of Chemical and Environmental Engineering, University of Nottingham Ningbo China, 199 Taikang East Road, Ningbo \\ 315100, China
}

Mike.George@nottingham.ac.uk; majed.chergui@epfl.ch

\footnotetext{
${ }^{\dagger}$ Now at : PULSE Institute for Ultrafast Energy Science, Stanford, USA

${ }^{\ddagger}$ Now at : CTR Carinthian Tech Research AG; Europastrasse 4/1, 9524 Villach/St. Magdalen, Austria.
} 


\section{Abstract}

Ferrous iron(II) hexacyanide in aqueous solutions is known to undergo photoionization and photoaquation reactions depending on the excitation wavelength. In order to investigate this wavelength dependence, we implemented ultrafast two-dimensional UV transient absorption spectroscopy, covering a range from 280 to $370 \mathrm{~nm}$ in both excitation and probing, along with UV pump/visible or IR continuum probe transient absorption spectroscopy and density functional theory (DFT) calculations. As far as photoaquation is concerned, we find that excitation of the molecule leads to ultrafast intramolecular relaxation to the lowest triplet state of the $\left[\mathrm{Fe}(\mathrm{CN})_{6}\right]^{4-}$ complex, followed by its dissociation into $\mathrm{CN}^{-}$and $\left[\mathrm{Fe}(\mathrm{CN})_{5}\right]^{3-}$ fragments and partial geminate recombination, all within $<0.5$ ps. The subsequent time evolution is associated with the $\left[\mathrm{Fe}(\mathrm{CN})_{5}\right]^{3-}$ fragment going from a triplet square pyramidal geometry, to the lowest triplet trigonal bipyramidal state in 3-4 ps. This is the precursor to aquation, which occurs in $\sim 20$ ps in $\mathrm{H}_{2} \mathrm{O}$ and $\mathrm{D}_{2} \mathrm{O}$ solutions, forming the $\left[\mathrm{Fe}(\mathrm{CN})_{5}\left(\mathrm{H}_{2} \mathrm{O} / \mathrm{D}_{2} \mathrm{O}\right)\right]^{3-}$ species, although some aquation also occurs during the 3-4 ps time scale. The aquated complex is observed to be stable on the microsecond timescale. For excitation below $310 \mathrm{~nm}$, the dominant channel is photooxidation with a minor aquation channel. The photoaquation reaction shows no excitation wavelength dependence up to $310 \mathrm{~nm}$, i.e. it reflects a Kasha Rule behaviour. In contrast, the photooxidation yield increases with decreasing excitation wavelength. The data from 2DUV, transient visible absorption and time resolved infrared (TRIR) absorption experiments are fully consistent. The various intermediates that appear in the TRIR studies are identified with the help of DFT calculations. These results provide a clear example of the energy dependence of various reactive pathways and of the role of spin-states in the reactivity of metal complexes. 


\section{Introduction}

Most of natural and preparative (bio)chemistry occurs in the liquid phase. The solvent molecules are by no means spectators as they may affect the outcome of the reactions in different ways, either dynamically by influencing the course of the reaction, e.g. hindering it as in the so-called cage effect, ${ }^{1}$ or by accelerating it, offering a driving force to the escape of products into the solvents; ${ }^{2,3}$ and/or statically by introducing relative energy shifts of the reactive potential surfaces on which the reactions (including photochemical ones) occur, according to the nature (covalent, charge transfer or, even Rydberg) of the states involved. ${ }^{4}$ For many years now, since the historical paper by Frank and Rabinowitsch, ${ }^{1}$ the physical effects of the solvent cage on photochemical reactions have intensely been studied by steady-state, ${ }^{4-6}$ and time-resolved methods ${ }^{2,3,6-8}$ on a wide class of systems. Less studied are the chemical pathways of the solution phase where intermediates react with solvent species, as discussed in a recent review. ${ }^{3}$ The complexity of such processes arises from the fact that either the excited solute or a nascent product sees a complex potential surface in its interaction with solvent molecules, which no longer just provide a barrier or a funnel to it, but participate in the chemical reaction depending on several aspects such as the nature of the reactants, their translational kinetic energy, their internal (electronic, vibrational, rotational) energy, their orientation, etc.

In attempting to describe liquid phase photochemistry, fundamental questions arise, which concern: a) the role of the initially excited state, b) the interplay between intramolecular relaxation (electronic or vibrational) in the solute/intermediates and the subsequent reactivity with solvent molecules; c) the role of spin states of both educts and products; d) the role of the excess energy dependence of the photochemical reactions. While a larger excess of kinetic energy of the fragments allows overcoming "physical" solvent cage barriers, ${ }^{5,9}$ the question remains open for the case of chemical reactions.

In addressing these questions, ligand substitution reactions and redox decomposition processes of metal complexes have been the topic of several mechanistic studies in coordination chemistry because of the fundamental role such reactions play in various chemical, biological and catalytic 
processes. ${ }^{10,11}$ In such systems, ultrafast intramolecular energy relaxation processes, such as internal conversion (IC), intersystem crossings (ISC) and intramolecular vibrational energy redistribution (IVR) in the solute may precede the reaction or be concurrent to it. These processes may also occur in the products if these are formed in excited states. In addition, intermolecular processes such as solvation dynamics, may take place concurrently with the above intramolecular ones, ${ }^{2}$ and the spin multiplicity plays a crucial role in the reactions leading to ligand substitution. ${ }^{12}$

Metal carbonyls have been among the most studied systems, probably because they offer the possibility to compare the photochemistry of the isolated molecule with that in condensed phases. Studies of the latter include UV photolysis in low temperature inert matrices, ${ }^{13}$ and several ultrafast spectroscopic studies in solution using transient absorption (TA) in the visible, ${ }^{14-19}$ and in the infrared. ${ }^{20-24}$ More recently, ultrafast studies on the photochemistry of $\mathrm{Fe}(\mathrm{CO})_{5}$ in solution have been pushed into the x-ray domain and an Fe K-edge x-ray absorption study was reported by Rose-Petruck and co-workers, ${ }^{25}$ while Wernet et al. ${ }^{26,27}$ implemented femtosecond $\mathrm{Fe}_{\mathrm{L}}$-edge resonant inelastic $\mathrm{x}$ ray scattering (RIXS) at the x-ray Free Electron Laser in Stanford. RIXS, which is a variant of x-ray emission spectroscopy, is a sensitive probe of the spin state of molecular systems. The studies on the photo-induced dynamics of $\mathrm{Fe}(\mathrm{CO})_{5}$ in $\mathrm{EtOH}$ suggest formation of the ${ }^{1}\left[\mathrm{Fe}(\mathrm{CO})_{4}(\mathrm{EtOH})\right]$ complex, and the role of the spin state of the $\mathrm{Fe}(\mathrm{CO})_{4}$ product is still debated. Wernet et al. ${ }^{26}$ reported a singlet complexation on sub-picosecond time scales, which was ascribed to a barrier-less bimolecular reaction where steric effects such as ethanol reorientation and concomitant hydrogen-bond breaking are absent or can easily be overcome. ${ }^{27}$ This fast photosubstitution is in line with reports of CO-ligand substitution of $\left[\mathrm{Cr}(\mathrm{CO})_{4}(\mathrm{bpy})\right]$ by solvent molecules, ${ }^{28-32}$ from a vibrationally "hot" excited state, alongside relaxation into two lower-lying unreactive states. In this case, dependence on excess energy was observed as the quantum yield of the reaction increased with excitation energy. It was argued that vibrational excitation provides sufficient distortion of the reacting molecule in the direction of the transition state whose structure was described as being similar to the undissociated excited molecule. 
Photoaquation is a particular case of the broader class of ligand substitution reactions in solutions and its understanding is particularly relevant to biology. ${ }^{33}$ It was recently studied in the case of cis-[Ru(bpy $\left.)_{2}\left(\mathrm{CH}_{3} \mathrm{CN}\right)_{2}\right] \mathrm{Cl}_{2}$ in water, showing the stepwise replacement of each $\mathrm{CH}_{3} \mathrm{CN}$ ligand by an $\mathrm{H}_{2} \mathrm{O}$ molecule, ${ }^{34}$ with the formation of the monoaqua cis- $\left[\mathrm{Ru}(\mathrm{bpy})_{2}\left(\mathrm{CH}_{3} \mathrm{CN}\right)\left(\mathrm{H}_{2} \mathrm{O}\right)\right]^{2+}$ taking place in $<100$ ps. One of the earliest examples of studies on photoaquation concerns metal cyanide systems ${ }^{35-38}$, such as $\left[\mathrm{Fe}^{\mathrm{II}}(\mathrm{CN})_{6}\right]^{4-}$, whose absorption spectrum is shown in Figure 1. The peculiarity of this system stems from the fact that it is a highly charged ion that has a strong interaction with the solvent. ${ }^{39-41}$ Both oxidation (Equation 1) and aquation (Equation 2) processes have been reported upon irradiation in the UV-visible range $\mathrm{e}^{42,43}$ :

$$
\begin{aligned}
& {\left[\mathrm{Fe}(\mathrm{CN})_{6}\right]^{4-*} \rightarrow\left[\mathrm{Fe}(\mathrm{CN})_{6}\right]^{3-}+e_{a q}^{-}} \\
& {\left[\mathrm{Fe}(\mathrm{CN})_{6}\right]^{4-*}+\mathrm{H}_{2} \mathrm{O} \rightarrow\left[\mathrm{Fe}(\mathrm{CN})_{5}\left(\mathrm{H}_{2} \mathrm{O}\right)\right]^{3-}+\mathrm{CN}^{-}}
\end{aligned}
$$

With the advent of ultrafast laser techniques, detailed femto- and picosecond TA studies of the photooxidation reaction (Equation 1) have been performed. ${ }^{44-47}$ It is generally believed this reaction is a consequence of direct or indirect population of the Charge-Transfer-to-Solvent (CTTS) state (Figure 1). ${ }^{42}$ A tentative assignment of the very short-lived ( $\left.<<60 \mathrm{fs}\right)$ CTTS-state, absorbing around $490 \mathrm{~nm}$ upon $267 \mathrm{~nm}$ excitation was made by ultrafast transient absorption (TA), ${ }^{45}$ but it was assumed that the initially populated ${ }^{1} \mathrm{~T}_{2 g}$-state relaxes into the CTTS state and therefore, the authors could not unambiguously distinguish between these two states. Ultrafast fluorescence up-conversion indeed failed to detect the CTTS state of $\left[\mathrm{Fe}(\mathrm{CN})_{6}\right]^{4-}{ }^{48}$ contrary to the case of aqueous iodide. ${ }^{49}$ 


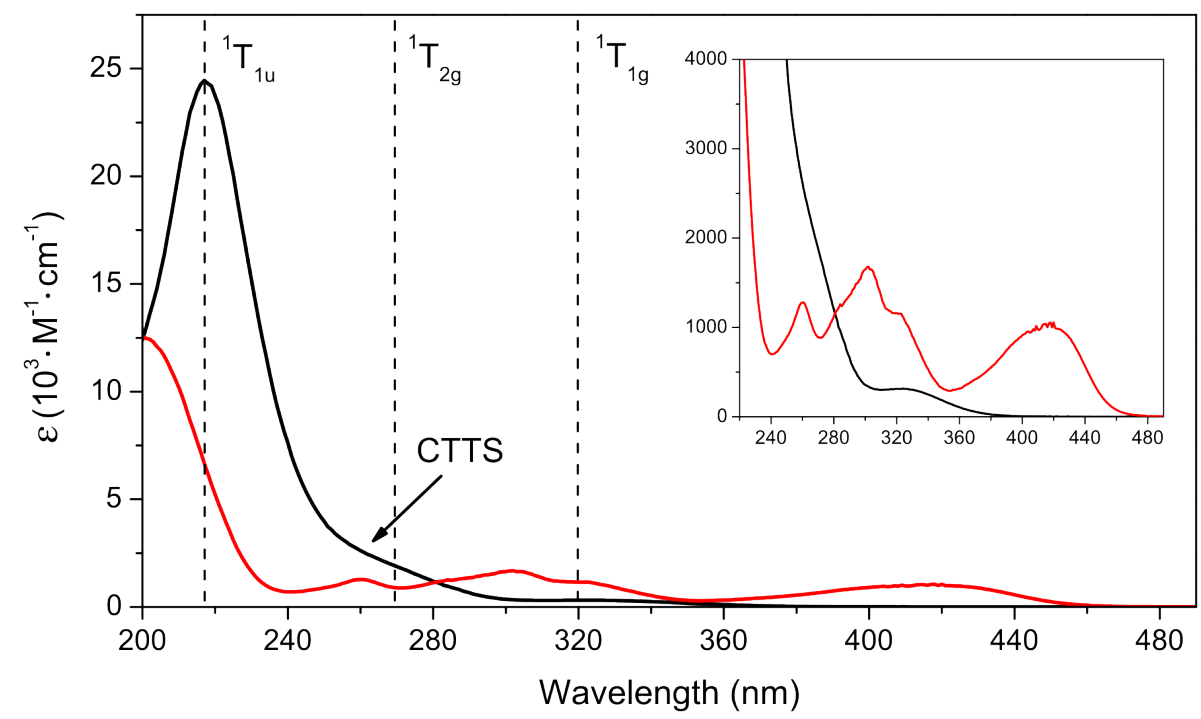

Figure 1. Extinction coefficients of solvated $\left[\mathrm{Fe}(\mathrm{CN})_{6}\right]^{4-}$ (black line) and $\left[\mathrm{Fe}(\mathrm{CN})_{6}\right]^{3-}$ (red line) in water. The vertical dashed lines show the energies of relevant excited states of $\left[\mathrm{Fe}(\mathrm{CN})_{6}\right]^{4-}$ in water. The inset shows magnified spectra, highlighting the lower-intensity transitions.

Anderson et $a l .{ }^{46}$ investigated the ionization process upon $266 \mathrm{~nm}$ excitation using time-resolved infrared (TRIR) spectroscopy. Their transient spectra in the $v(C N)$ region in $\mathrm{D}_{2} \mathrm{O}$, show a significant baseline offset, which they attributed to a direct precursor of the pre-solvated electron generated by excitation of the CTTS state. Furthermore, they observed a short-lived absorption peak red-shifted by ca. $2 \mathrm{~cm}^{-1}$ from the parent ion (at $2038 \mathrm{~cm}^{-1}$ ) as well as a band at $2114 \mathrm{~cm}^{-1}$ due to the photoionized product $\left[\mathrm{Fe}(\mathrm{CN})_{6}\right]^{3-}$. The appearance of the latter at the earliest time delays indicates electron-ejection in less than $200 \mathrm{fs}^{46}$

The reaction shown in Equation 2 is less well understood. It is triggered by excitation of weak Laporte-forbidden ligand-field (LF or metal-centered) states $\left(\varepsilon \lesssim 400 \mathrm{M}^{-1} \cdot \mathrm{cm}^{-1}\right)$ for $\lambda>300 \mathrm{~nm}^{50}$ or, with a lower yield, in the 245 - $300 \mathrm{~nm}$ range, where the CTTS and LF bands overlap (Figure 1). Using flash photolysis, Shirom and Stein $^{43}$ identified the photoaquated species via an absorption band in the 380-480 nm region which they attributed to the ${ }^{1} A_{1} \rightarrow{ }^{1} E(1)^{51}$ transition of the $\left[\mathrm{Fe}(\mathrm{CN})_{5}\left(\mathrm{H}_{2} \mathrm{O}\right)\right]^{3-}$ 
complex, and concluded that it is formed within one nanosecond. Quantum yields for aquation ( $\left.\phi_{\mathrm{aq}}\right)$ were found to depend on the excitation wavelength, $\mathrm{pH}$ and on concentration ${ }^{35,52}$ and the extracted values have large uncertainties. In $10 \mathrm{mM}$ neutral solutions, $\phi_{a q} \sim 0.2$ was reported for $313 \mathrm{~nm}$ and 365 $\mathrm{nm}$ excitation and $\sim 0.1$ for $254 \mathrm{~nm}$ excitation, indicating that an increasing energy decreases $\phi_{a q}$ and pointing to another competing relaxation channel at higher energies, ${ }^{42}$ which is most likely the photooxidation channel.

Recently, Reinhard et al. reported a x-ray absorption spectroscopy study with 70 ps time resolution of aqueous ferric and ferrous hexacyanide upon $355 \mathrm{~nm}$ and $266 \mathrm{~nm}$ excitation, combined with quantum chemical calculations. ${ }^{48}$ In the case of the ferrous complex upon $355 \mathrm{~nm}$ excitation, they identified the aquated $\left[\mathrm{Fe}(\mathrm{CN})_{5}\left(\mathrm{H}_{2} \mathrm{O}\right)\right]^{3-}$ species, confirming the conclusions of optical studies, ${ }^{43}$ and they determined its molecular structure. Upon $266 \mathrm{~nm}$ excitation, the main photoproduct was the ferric hexacyanide complex. The limited time resolution of their experiment did not allow for the time scale of photoaquation and therefore, its mechanism to be determined.

It is indeed unclear if photoaquation of $\left[\mathrm{Fe}(\mathrm{CN})_{6}\right]^{4-}$ starts by dissociation of a $\mathrm{CN}$-ligand followed by binding of a solvent molecule or if the process is concerted. In either case, the next question is whether dissociation starts from the lowest lying singlet ${ }^{1} \mathrm{~T}_{1 g}$ state or the system undergoes fast ISC to the ${ }^{3} \mathrm{~T}_{\mathrm{lg}}$ or even the ${ }^{5} \mathrm{~T}_{2 \mathrm{~g}}$ state, which was theoretically predicted ${ }^{53}$ but never identified. By measuring small but positive activation volumes of the ferrocyanide photoaquation reaction, Finston and Drickamer $^{54}$ excluded a purely associative mechanism, which would involve an intermediate with bond formation between the complex and the solvent molecule. They argued that photoaquation is likely to proceed via a dissociative interchange pathway in which ligand-to-metal bond breaking and solvent-tometal bond formation are concerted. This seems consistent with density functional theory (DFT) calculations ${ }^{53}$ which estimated the ground state dissociation energy to $6.2 \mathrm{eV}$ per Fe-CN bond, while photoaquation already occurs for $3.4 \mathrm{eV}$ excitation into the ${ }^{1} \mathrm{~T}_{1 g}$ state. However, these calculations concern the isolated molecule, excluding solvent effects, which may strongly affect the energetics of the system. Indeed, an association mechanism may be compatible with recent $\mathrm{x}$-ray ${ }^{39,41}$ and $\mathrm{IR}^{40,55}$ 
studies, hinting to a specific interaction between the solute and water molecules in the ground state of the complex.

The occurrence of excitation energy dependent reaction channels (oxidation, aquation) in the photochemistry of $\left[\mathrm{Fe}(\mathrm{CN})_{6}\right]^{4-}$ and the fact that it is a highly charged educt make it an ideal system for the description of solution phase ultrafast chemical dynamics. We recently demonstrated the power of ultrafast 2-dimensional (2D) ultraviolet (UV) transient absorption (TA) spectroscopy, ${ }^{56-58}$ to disentangle concurrent excitation energy-dependent relaxation channels in biological and chemical systems. Here, we combine it with ultrafast UV pump/visible continuum probe and UV pump/IR continuum probe ${ }^{59}$ TA spectroscopy to disentangle the excitation wavelength dependence of the processes described by Equations 1 and 2 in aqueous $\left[\mathrm{Fe}(\mathrm{CN})_{6}\right]^{4-}{ }^{42,43}$ The present combination of techniques allows an unambiguous assignment of the photoproducts and of their time scales of formation for excitation wavelengths below and above $310 \mathrm{~nm}$ in $\mathrm{H}_{2} \mathrm{O}$ and $\mathrm{D}_{2} \mathrm{O}$ covering the time range from $<1$ ps to $100 \mu \mathrm{s}$. Finally, DFT calculations have been carried out to simulate the geometries and vibrational frequencies of $\left[\mathrm{Fe}(\mathrm{CN})_{6}\right]^{4-}$ and of some of its predicted photoproducts, both in vacuo and in solution. The results suggest that following photoexcitation, the system relaxes to the lowest triplet state from which dissociation occurs, leading to the formation of a triplet $\left[\mathrm{Fe}(\mathrm{CN})_{5}\right]^{3-}$ complex. The latter undergoes conformational changes prior to binding of a water molecule. Further details about the experimental and computational set-ups and procedures as well as the data treatment are given in the supporting information (SI).

\section{Experimental}

\section{Time-resolved Infrared (TRIR) spectroscopy}

TRIR spectroscopy was carried out using the ULTRA facility located at the Rutherford Appleton Laboratory, using time resolved multiple probe spectroscopy $\left(\mathrm{TR}^{\mathrm{M}} \mathrm{PS}\right)$ on the ULTRA and LIFEtime instruments. Detailed descriptions of the experimental setups have been published previously. ${ }^{59,60}$ 
Briefly, the $\mathrm{TR}^{\mathrm{M}} \mathrm{PS}$ experiment utilizes a pump-probe-probe-probe... recording scheme afforded by synchronizing two oscillators with the pump laser tuned to 320 or $266 \mathrm{~nm}$ by optical parametric amplification (OPA) while the mid-IR probe is generated using OPAs with difference-frequency mixing units. The pump-probe time delay is controlled using a combination of electronic and optical delays, which allows time-delays from ps to ms to be achieved in a single experiment. The instrument response $\left(\tau_{\mathrm{IRF}, \mathrm{IR}}\right)$ is approximately 300 to $400 \mathrm{fs}$. The pump pulse was set to $c a .1 \mu \mathrm{J} / \mathrm{pulse}$ at the sample using a neutral density filter. Pump and probe beam polarizations were set at the magic angle. Where necessary a portion of the probe beam was dispersed onto an MCT detector as a reference, while the remainder was passed through the sample, dispersed by grating monochromators and detected by 128 channel linear MCT array detectors. $\left[\mathrm{Fe}(\mathrm{CN})_{6}\right]^{4-}$ samples were measured in unbuffered $\mathrm{H}_{2} \mathrm{O}$ and $\mathrm{D}_{2} \mathrm{O}$ $(18 \mathrm{mM})$ and were circulated in a closed flow system attached to a Harrick solution cell with $\mathrm{CaF}_{2}$ windows, spaced by $100 \mu \mathrm{m}$ with Teflon spacers. The sample cells were rastered in the two dimensions orthogonal to the direction of beam propagation in order to minimize sample breakdown and localized heating. The spectral resolution is $c a .1 .5 \mathrm{~cm}^{-1}$.

\section{Two-dimensional Ultraviolet (2D-UV) spectroscopy:}

A detailed description of the set-up was recently published. ${ }^{56-58}$ Laser pulses from a cryogenically cooled Ti:Sapphire amplifier (Wyvern, KM Labs) running at $20 \mathrm{kHz}$, pump a non-collinear optical parametric amplifier (NOPA, TOPAS white, Light Conversion) whose output serves as primary light source of the experiment. One third of the generated visible light passes a motorized delay line and subsequently an achromatic frequency doubling stage, which delivers broad band UV probe pulses in the $270-360 \mathrm{~nm}$ range. After the sample, probe pulses are dispersed by a fiber coupled spectrograph and detected on a shot-to-shot basis with a CMOS linear image array. The remaining two thirds of the NOPA output are directed through a chopper which is phase-locked to half the repetition rate of the laser system $(10 \mathrm{kHz})$ and passes a motorized BBO-crystal whose angle is adjustable with respect to 
the incident beam in order to allow for a frequency tunable narrow-band pump beam without significantly changing the spatial overlap with the probe beam. Polarizations of pump and probe beams were parallel and at all pump wavelengths used, fluences were $0.6 \mathrm{~mJ} / \mathrm{cm}^{2}$.

Samples of $30 \mathrm{mM}\left[\mathrm{Fe}(\mathrm{CN})_{6}\right]^{4-}$ in unbuffered aqueous solution (deionized $\mathrm{H}_{2} \mathrm{O}$ ) were prepared from purchased potassium ferrocyanide $\left(\mathrm{K}_{4} \mathrm{Fe}(\mathrm{CN})_{6} \cdot 3 \mathrm{H}_{2} \mathrm{O}\right.$, Sigma Aldrich) and measured in a $100 \mu \mathrm{m}$ liquid jet. Pure solvent scans did not yield any signals apart from cross-phase modulation (CPM), whose width we use to estimate the instrumental response function of $\tau_{I R F, U V} \approx 150 \mathrm{fs}$. However the relatively small sample signals may be distorted up to ca. $300 \mathrm{fs}$ and we refrain from interpreting data at shorter delays.

\section{UV-pump/visible-probe experiments}

To complement the 2D UV transient absorption studies, we also carried out UV pump/visible probe measurements of aqueous $\left[\mathrm{Fe}(\mathrm{CN})_{6}\right]^{4-}$ with a white light continuum probe in the $380-480 \mathrm{~nm}$ region generated from a small portion of the $800 \mathrm{~nm}$ fundamental. The TOPAS white output and motorized BBO-crystal rotation were optimized for efficient pumping at $323 \mathrm{~nm}$ with ca. $1.3 \mathrm{~mJ} / \mathrm{cm}^{2}$. The number of detector counts is significantly lower in the visible probe region and due to noise limitations in this case, we used a $500 \mu \mathrm{m}$ flow cell instead of the thinner liquid jet used in the 2D UV experiment. The larger thickness was chosen in order to minimize the accumulation of photoproducts at the cell windows. In addition, during the measurements, the cell was regularly moved within the spatial pump-probe overlap region, ensuring the integrity of the accumulated signal scans during the measurements. In order to maintain an optical density of $\sim 0.3$ a sample concentration of $0.02 \mathrm{M}$ was chosen. The relatively large sample thickness increases the instrument response function from $\sim 150$ fs 
in the UV-probe experiments to $\tau_{I R F \text {, visible }} \sim 690 \mathrm{fs}$ in the visible-probe experiments as determined from the cross-phase modulation (CPM) on pure water solutions. Further support for this decrease in timeresolution at earlier times stems from measurements of PPO in cyclohexane where we measured a comparable $\tau_{I R F, v i s i b l e}$ even though the signal rise time is known to be much faster than $150 \mathrm{fs}$. Pump and probe polarizations were at magic angle.

\section{Results}

The photochemistry $\left[\mathrm{Fe}(\mathrm{CN})_{6}\right]^{4-}$ in aqueous solutions had previously been reported ${ }^{42,43}$ for only a few fixed excitation wavelengths. In addition, the ultrafast visible ${ }^{45}$ and $\mathrm{IR}^{46}$ studies carried out so far only considered excitation into the CTTS states of $\left[\mathrm{Fe}(\mathrm{CN})_{6}\right]^{4-}$ at $266 \mathrm{~nm}$ (Figure 1 and Equation 1). Here we complement these studies by covering the excitation range from 280 to $330 \mathrm{~nm}$, using twodimensional UV transient absorption spectroscopy in $\mathrm{H}_{2} \mathrm{O}$ and we focus on specific excitation wavelengths using ps-TRIR in $\mathrm{H}_{2} \mathrm{O}$ and $\mathrm{D}_{2} \mathrm{O}$. Given the scarcity of ultrafast studies, it is important to benchmark our TRIR experiments against those previously reported under $266 \mathrm{~nm}$ excitation. ${ }^{46}$

TRIR spectra of $\left[\mathrm{Fe}(\mathrm{CN})_{6}\right]^{4-}$ in $\mathrm{H}_{2} \mathrm{O}$ and $\mathrm{D}_{2} \mathrm{O}$, at fixed time delays following excitation at a pump wavelength $\left(\lambda_{\text {pump }}\right)$ of $266 \mathrm{~nm}$ are shown in Figures S1 and S2. There is a significant baseline offset at early times. These results are in agreement with previous studies that assigned the change in the mid-IR baseline to the precursor of the pre-solvated electron. ${ }^{46}$ The parent band $\left(2038 \mathrm{~cm}^{-1}\right)$ is bleached and a new transient peak at $2117 \mathrm{~cm}^{-1}$ is visible within $\sim 1 \mathrm{ps}$, with the earlier times obscured by the baseline offset mentioned above. The band at $2117 \mathrm{~cm}^{-1}$ is due to formation of the ferricyanide ion, $\left[\mathrm{Fe}(\mathrm{CN})_{6}\right]^{3-}$, consistent with ref. ${ }^{46}$. The kinetic traces of significant bands for the sample in $\mathrm{H}_{2} \mathrm{O}$ are shown in Figure $\mathrm{S} 3$ and are similar in the case of $\mathrm{D}_{2} \mathrm{O}$. There is a partial recovery of the parent with a concomitant partial decrease of the intensity of the $2117 \mathrm{~cm}^{-1}$ band observed on the nanosecond timescale, fully consistent with the partial recombination of the solvated electron with $\left[\mathrm{Fe}(\mathrm{CN})_{6}\right]^{3-} .{ }^{47}$ The $\left[\mathrm{Fe}(\mathrm{CN})_{6}\right]^{3-}$ band then persists up to the longest time delays in our experiment (Figure S2). At early times (Figure 
S3(a)), an apparent partial recovery of the parent bleach band at $2038 \mathrm{~cm}^{-1}$ occurs on a time scale of $\tau=$ $20 \pm 5$ ps. The band frequencies and their timescales are summarised in Table 1. A band is also observed at $\sim 2088 \mathrm{~cm}^{-1}$ at early times, whose decay seems to be independent to the $\left[\mathrm{Fe}(\mathrm{CN})_{6}\right]^{3-}$ band at $2117 \mathrm{~cm}^{-1}$. We discuss it further below. In order to disentangle contributions from different photochemical channels we now turn to 2D UV TA spectroscopy.

Figure 2 shows the 2D UV TA spectra $(\Delta A)$ of aqueous $\left[\mathrm{Fe}(\mathrm{CN})_{6}\right]^{4-}$ as a function of pump $\left(\lambda_{\text {pump }}\right)$ and probe $\left(\lambda_{\text {probe }}\right)$ wavelengths at selected delays $(\Delta \mathrm{t}=0.5,1,4$ and $50 \mathrm{ps})$. After $50 \mathrm{ps}$, there is only little change in the observed transient signals, which remain stable up to the limit of our temporal window ( $\sim 780 \mathrm{ps}$ ). Two main trends characterize the time and spectral evolution of the system as a function of $\lambda_{\text {pump }}$ : one below $\sim 310 \mathrm{~nm}$, and the other above. There is a clear dependence of the appearance of spectral features on $\lambda_{\text {pump }}$ and upon excitation into the CTTS region (ca. $290 \mathrm{~nm}$ ), the transient ground state $\left[\mathrm{Fe}(\mathrm{CN})_{6}\right]^{3-}$ absorption bands can be identified, resulting from photooxidation (dashed red line in $50 \mathrm{ps}$ window). The $\left[\mathrm{Fe}(\mathrm{CN})_{6}\right]^{3-}$ band is formed within our time resolution ( 150 fs) and partially decays due recombination with the photoejected electrons.

At lower energy, in the region of the ${ }^{1} \mathrm{~T}_{1 g}$ absorption (blue line in Figure 2), a $<1$ ps-lived positive signal appears, which is most pronounced in the highest-energy part of the probe range $(<280$ $\mathrm{nm})$. At $\lambda_{\text {probe }}<340 \mathrm{~nm}$, this signal decays and becomes negative such that by $\sim 50 \mathrm{ps}$, it resembles the inverted static $\left[\mathrm{Fe}(\mathrm{CN})_{6}\right]^{4-}$ absorption spectrum (Figure 2, 50 ps window, red line), reflecting a longlived ground state bleach. At $\lambda_{\text {probe }}>340 \mathrm{~nm}$, the signal remains positive, indicating a long-lived absorption band. Therefore, direct excitation of the ${ }^{1} \mathrm{~T}_{1 g}$ state yields long-lived species, which is (are) not explained in terms of a photooxidized product, $\left[\mathrm{Fe}(\mathrm{CN})_{6}\right]^{3-}$. In the following, we will mainly focus on results obtained at $\lambda_{\text {pump }}=284 \mathrm{~nm}$ and $\lambda_{\text {probe }}=320 \mathrm{~nm}$, which are representative of the processes described by Equations 1 and 2 above. 


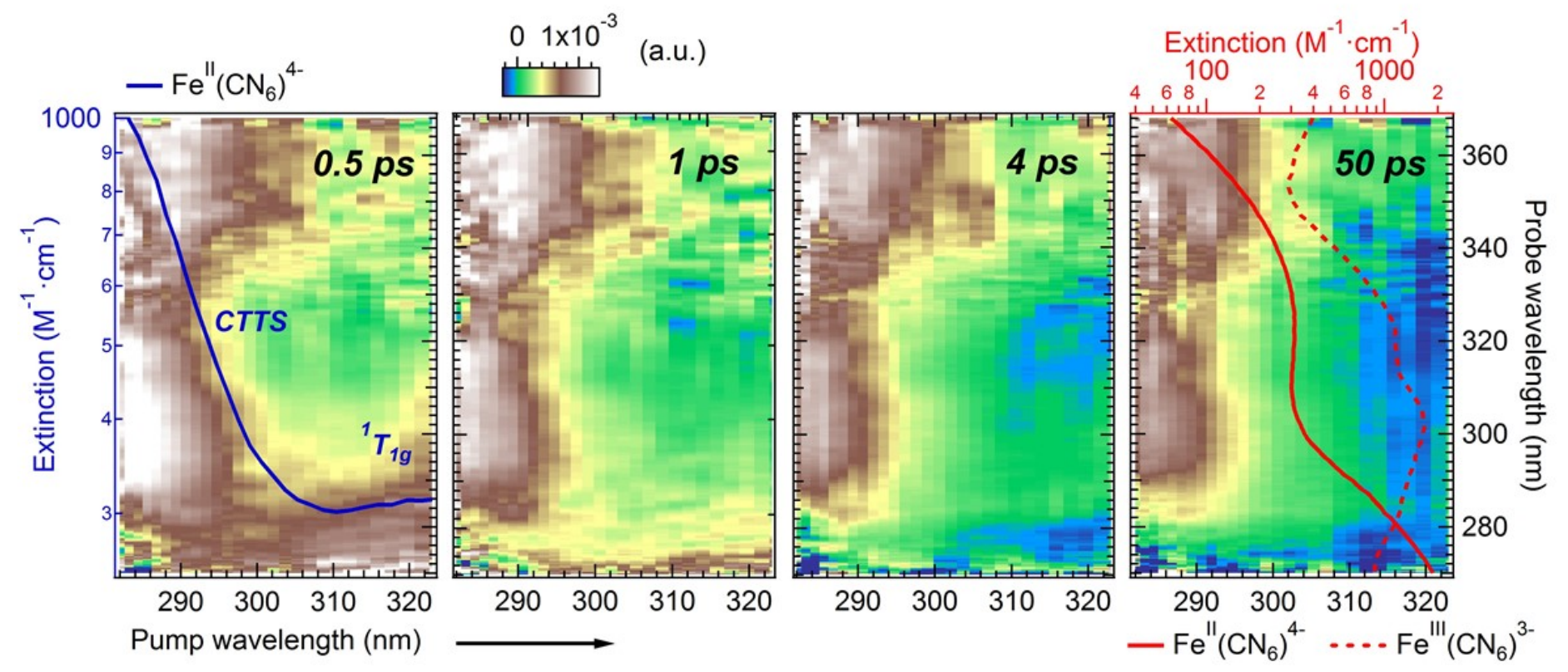

Figure 2. Pump intensity corrected $2 \mathrm{D}$ spectra of aqueous $\left[\mathrm{Fe}(\mathrm{CN})_{6}\right]^{4-}$ as a function of pump (horizontal axis) and probe (vertical left axis) wavelength. The extinction coefficient (in $\mathrm{M}^{-1} \cdot \mathrm{cm}^{-1}$ ) of $\left[\mathrm{Fe}(\mathrm{CN})_{6}\right]^{4-}$ vs. pump wavelength is represented by the blue line (left vertical axis) in the leftmost panel and vs. probe wavelength by the solid red line (horizontal upper axis) in the rightmost panel. The extinction coefficient of $\left[\mathrm{Fe}(\mathrm{CN})_{6}\right]^{3-}$ is shown by the dashed red line. CTTS and ${ }^{1} \mathrm{~T}_{1 \mathrm{~g}}$ regions of the $\left[\mathrm{Fe}(\mathrm{CN})_{6}\right]^{4-}$ extinction coefficient are indicated.

As discussed before, previous time-resolved optical and x-ray studies, ${ }^{42,43,46,48}$ showed that photoaquation is the favored process after ${ }^{1} \mathrm{~T}_{1 g}$ excitation $(320 \mathrm{~nm})$, while the signal upon $<300 \mathrm{~nm}$ excitation is predominantly due to photooxidation. Figures 3(a) and (c) compare the transient spectra at $284 \mathrm{~nm}$ and $320 \mathrm{~nm}$ excitation, at different integrated pump-probe delay windows. Relatively large temporal integration ranges are chosen for enhanced clarity but all conclusions are confirmed by averages over smaller ranges (Figures S4 and S5). Both figures show a dominant absorption in the blue most part $(<300 \mathrm{~nm})$ of the probe range, which quickly disappears (within 1-2 ps), leaving the transient with a profile that does not evolve much thereafter. In Figure 3(a), the transients at later times are dominated by the broad absorption of the ${ }^{2} \mathrm{~T}_{2 g} \rightarrow{ }^{2} \mathrm{~T}_{2 u}\left(\mathrm{t}_{2 u} \pi \rightarrow \mathrm{t}_{2 g} \pi\right)$ ligand to metal charge transfer 
$(\mathrm{LMCT})$ band of $\left[\mathrm{Fe}(\mathrm{CN})_{6}\right]^{3-}$ and the solvated electron (as demonstrated below). ${ }^{47}$ In Figure 3(c), the transients show weak negative (bleach) and positive signals, which we discuss hereafter.

The solvated electron is characterized by an extinction coefficient that is much larger than that of all other photoproducts as can be seen in Figure S6. This induces a significant offset of the signals at all time delays. In order to identify the spectral features in Figures 3(a) and (c), the extinction coefficients $(\varepsilon)$ of the expected photoproducts were used to simulate the final transient spectra. For the transient obtained by $284 \mathrm{~nm}$ excitation, the extinction coefficient is calculated as $\varepsilon_{284 \mathrm{~nm}}=8 \cdot 10^{-7}$.

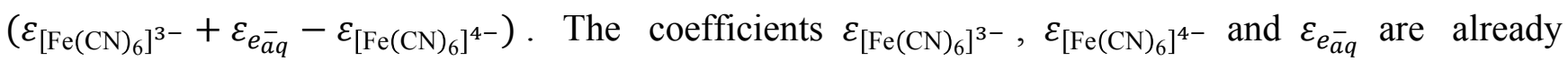
known $^{61}$ (Figure S6). The resulting $\varepsilon_{284 \mathrm{~nm}}$ is shown as a black dashed line in Figure 3(a) and it overall agrees with the transient spectrum at the longest time delays (purple trace) despite some deviations between 295 and $330 \mathrm{~nm}$.

In the case of $320 \mathrm{~nm}$ excitation, the most likely final product is the aquated species. We therefore calculate $\varepsilon_{320 \mathrm{~nm}}=8 \cdot 10^{-7} \cdot\left(\varepsilon_{\left[\mathrm{Fe}(\mathrm{CN})_{5}\left(\mathrm{H}_{2} \mathrm{O}\right)\right]^{3-}}-\varepsilon_{\left[\mathrm{Fe}(\mathrm{CN})_{6}\right]^{4-}}\right)$, where the value of $\varepsilon_{\left[\mathrm{Fe}(\mathrm{CN})_{6}\left(\mathrm{H}_{2} \mathrm{O}\right)\right]^{3-}}$ is taken from literature. ${ }^{62,63}$ The result is shown as a black dashed line in Figure $3(\mathrm{c})$ and it nicely reproduces the shape of the longest time delay transient, confirming the presence of the photoaquated species $\left[\mathrm{Fe}(\mathrm{CN})_{5}\left(\mathrm{H}_{2} \mathrm{O}\right)\right]^{3-}$. The rising signal in the low energy part of the spectrum therefore likely reflects the tail of the ${ }^{1} \mathrm{~A}_{1} \rightarrow{ }^{1} \mathrm{E}(1)$ absorption band of $\left[\mathrm{Fe}(\mathrm{CN})_{5}\left(\mathrm{H}_{2} \mathrm{O}\right)\right]^{3-}$, which is centered around $440 \mathrm{~nm}$ in the static absorption spectrum.

This is confirmed by probing at lower energies, in the $380-480 \mathrm{~nm}$ region, and Figure 4(a) shows the TA spectra in this region, averaged over different temporal windows. Indeed, absorption features appear within $\sim 0.7 \mathrm{ps}$ with maxima at $\sim 400 \mathrm{~nm}$ and $>470 \mathrm{~nm}$. After a fast initial decay, further evolution of the transient occurs with minor changes around $410 \mathrm{~nm}$. At times $>15 \mathrm{ps}$, the TA spectrum (dark blue and purple traces) converges to the static difference spectrum of the $\left[\mathrm{Fe}(\mathrm{CN})_{5}\left(\mathrm{H}_{2} \mathrm{O}\right)\right]^{3-}{ }^{1} A_{1} \rightarrow{ }^{1} E(1)$ transition $)$ and $\left[\mathrm{Fe}(\mathrm{CN})_{6}\right]^{4-}$ absorption $\left(\varepsilon_{320 \mathrm{~nm}}\right.$, black dashed trace). 

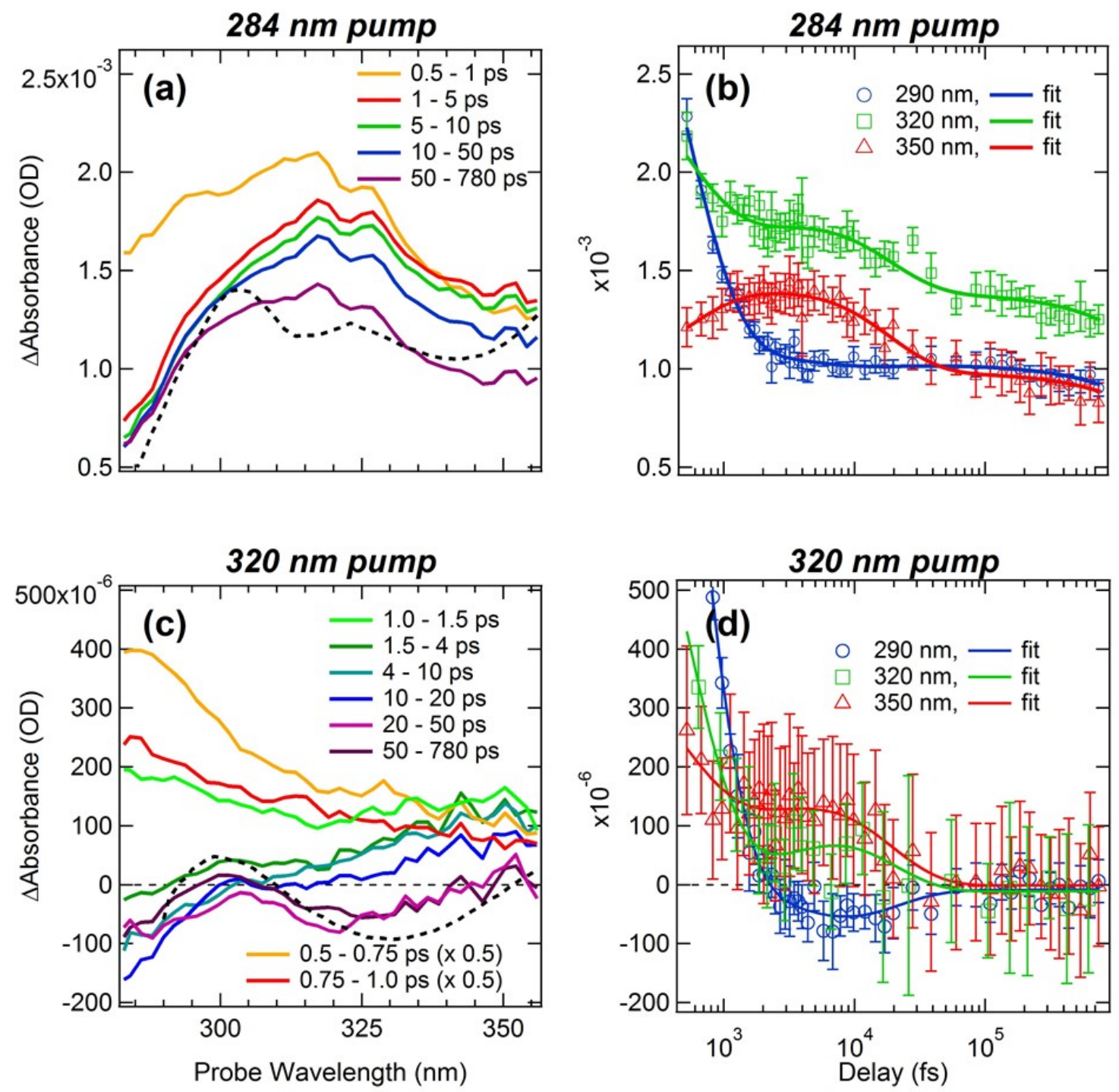

Figure 3. Averaged transient spectra and kinetic traces of aqueous $\left[\mathrm{Fe}(\mathrm{CN})_{6}\right]^{4-}$ excited at $(\mathrm{a}, \mathrm{b}) 284 \mathrm{~nm}$ and $(\mathrm{c}, \mathrm{d}) 320 \mathrm{~nm}$. The dashed black line in (a) corresponds to $\varepsilon_{284 \mathrm{~nm}}$ and the dashed line in (c) corresponds to $\varepsilon_{320} \mathrm{~nm}$, as defined in the text. Kinetic traces and fits with timescales (Table 1) derived from the full 3-dimensional dataset are shown in (b) and (d). 

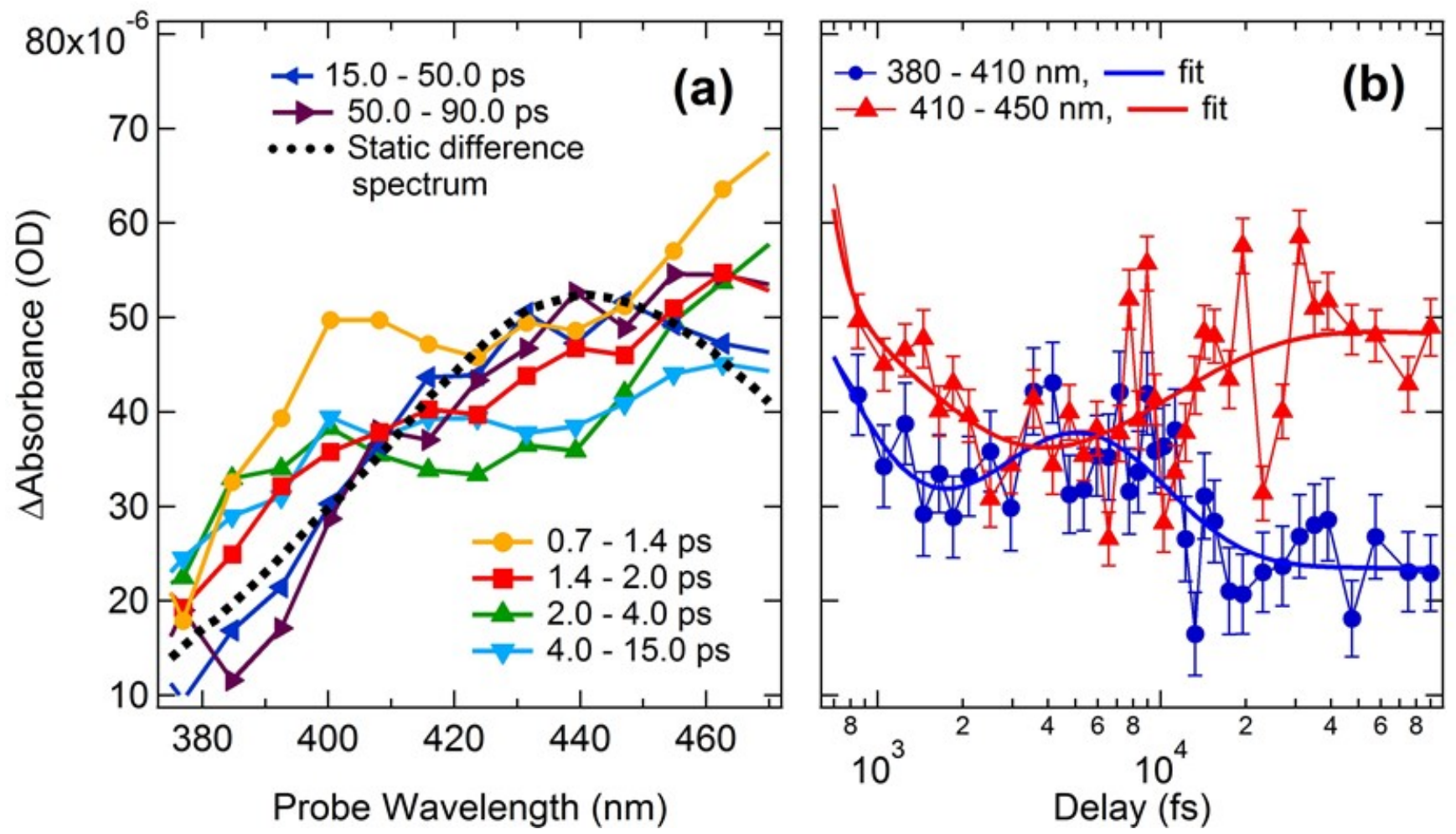

Figure 4. Visible probe transients following $323 \mathrm{~nm}$ excitation of aqueous $\left[\mathrm{Fe}(\mathrm{CN})_{6}\right]^{4-}$. (a) Averaged spectra in the vicinity of the ${ }^{1} \mathrm{~A}_{1}$ $\rightarrow{ }^{1} \mathrm{E}(1)$ absorption band of the aquated species. The dashed black line is the modelled static absorption difference of the $\left[\mathrm{Fe}(\mathrm{CN})_{5}\left(\mathrm{H}_{2} \mathrm{O}\right)\right]^{3-}$ and $\left[\mathrm{Fe}(\mathrm{CN})_{6}\right]^{4-}$ species $\left(0.1 \cdot \varepsilon_{320}\right.$, see Figure 3) (b) Smoothed kinetic traces and fits with fixed timescales derived from the UV dataset (Table 1).

In order to gain a quantitative understanding of the 2D UV data, a global fit (GF) was carried out. Four exponential timescales are required in the photoaquation regime $(320 \mathrm{~nm}$ excitation, see below). For both $284 \mathrm{~nm}$ and $320 \mathrm{~nm}$ excitation, transient spectra at delays around $\sim 50$ ps still display small changes (Figures 3, S4 and S5), presumably due to slow, non-exponential recombination kinetics of the corresponding photochemical species, these changes are not properly captured by our multiexponential kinetic model. Therefore, the inclusion of an additional timescale is avoided in favor of a more stable fit model. This strategy and the extracted time constants are fully confirmed by the IR results presented below. Fitting the initial decay requires two exponential timescales $\left(\tau_{1}=0.5 \mathrm{ps}, \tau_{2}=4\right.$ 
ps). ${ }^{\S}$ An additional time constant of $\sim 16 \mathrm{ps}\left(\tau_{3}\right)$ is needed to capture the intermediate times. Representative kinetic traces for $284 \mathrm{~nm}$ and $320 \mathrm{~nm}$ excitation are shown in Figures 3(b) and 3(d) together with their fits. The time constant for the longest process obtained from the GF of the 2D UV dataset is $\tau_{4} \sim 7 \mathrm{~ns}\left(\tau_{4}\right)$ but this value should be taken only as an order of magnitude, due to the limited range of the data set. The fitted time constants are summarized in Table 1.

To disentangle the spectral components making up the full 2D UV data set, we also applied a singular value decomposition (SVD) as described in refs ${ }^{58,64}$ and in $\S$ S4. The SVD analysis of the 2D UV data set yields 2D Decay Associated Dispersed Action Spectra (DADAS) ${ }^{58}$ associated with the four decay constants $\left(\tau_{1}=0.5 \pm 0.1 \mathrm{ps}, \tau_{2}=4 \pm 2 \mathrm{ps}, \tau_{3}=16 \pm 3 \mathrm{ps}, \tau_{4} \sim 7 \mathrm{~ns}\right)$. All spectra are subsequently corrected for the photolysis yield ( $\S \mathrm{S} 2)$ in order to obtain signal magnitudes, which are directly comparable with quantum yields. The extracted four DADAS are plotted in Figure S7 and their detailed description is given in $\S \mathrm{S} 4.2$. The consistency of the extracted parameters is confirmed by a fit of the kinetic traces integrated over the spectral regions $380-410 \mathrm{~nm}$ and $410-470 \mathrm{~nm}$. The choice of these regions is justified by the spectral evolution shown in Figure 4(a). Assuming that the above four timescales of the UV-probe experiment also occur in the visible-probe region, we obtain a satisfactory fit of the kinetics, notwithstanding the poor signal-to-noise ratio (Figure 4(b)). Since the visible probe measurements were limited by an IRF of $\tau_{\text {IRF,visible }} \sim 690 \mathrm{fs}$ (see experimental section), we left out the fastest component in this analysis. The $\sim 7 \mathrm{~ns}$ component appears in the analysis of both the $284 \mathrm{~nm}$ and the $320 \mathrm{~nm}$ excitation data. As already mentioned, this timescale is much longer than the time range of the measurements and is therefore, only indicative of slow processes that reflect the long-lived species upon $320 \mathrm{~nm}$ excitation and/or the electron-ferricyanide recombination upon $284 \mathrm{~nm}$ excitation.

With these elements in hand, we then extract the DAS in the combined UV-visible probe range for $320 \mathrm{~nm}$ excitation, which are shown in Figure 5(b), while Figure 5(a) shows the steady state spectra of $\left[\mathrm{Fe}(\mathrm{CN})_{6}\right]^{4-}$ and of the aquated form. The $0.5 \mathrm{ps}\left(\tau_{1}\right)$ DAS is only constructed for the UV range due to the limited time resolution in the visible range, and it essentially shows the fast decay of the induced

\footnotetext{
$\S$ A stretched exponential fit was attempted but it poorly reproduced the data.
} 
absorption peaking below $280 \mathrm{~nm}$. In the visible range, an absorption band centered at $\lambda_{\text {probe }} \sim 460 \mathrm{~nm}$ also appears within the time resolution of the experiment (see Figure 4(a)). The 4 ps $\left(\tau_{2}\right)$ DAS reflects a second, slower decay component of the induced UV $(<320 \mathrm{~nm})$ absorption and some spectral intensity redistribution from $410-480 \mathrm{~nm}$ to $380-410 \mathrm{~nm}$ of the absorption in the visible range. The $16 \mathrm{ps}\left(\tau_{3}\right)$ DAS displays a ground state bleach recovery below $320 \mathrm{~nm}$ and it mirrors the 4 ps DAS above $330 \mathrm{~nm}$, pointing to an intensity redistribution back from $380-410 \mathrm{~nm}$ to $410-480 \mathrm{~nm}$. The prominent negative feature of the $16 \mathrm{ps}$ DAS in the $410-480 \mathrm{~nm}$ region reflects the rise of the $\sim 7 \mathrm{~ns}\left(\tau_{4}\right)$ DAS that has a broad and intense absorption covering the $380-480 \mathrm{~nm}$ range. The $\sim 7 \mathrm{~ns}$ DAS is nicely reproduced by $\varepsilon_{320 \mathrm{~nm}}$ (see above), and it can therefore be assigned predominantly to the $\left[\mathrm{Fe}(\mathrm{CN})_{5}\left(\mathrm{H}_{2} \mathrm{O}\right)\right]^{3-}$ complex. As seen from the scaling factor in Figure 4(a), the photolysis yield was considerably lower in the visible probe experiments. This is consistent with calculated excitation yields (see § S2) and the larger sample thickness in the latter experiment, which is expected to enhance absorption effects. Therefore, the dynamics in the $\lambda_{\text {probe }}<320 \mathrm{~nm}$ range point to the decay of a single photo-induced species in $0.5 \mathrm{ps}$ and 4 ps while the range $\lambda_{\text {probe }}>320 \mathrm{~nm}$ shows a 4 ps band splitting/broadening process, followed by band merging/narrowing in $16 \mathrm{ps}$, which is indicative of structural and symmetry changes. The appearance time of features assigned to $\left[\mathrm{Fe}(\mathrm{CN})_{5}\left(\mathrm{H}_{2} \mathrm{O}\right)\right]^{3-}$ is $\sim 16 \mathrm{ps}$, while the nature of the absorption bands present at the earliest times and their subsequent spectral evolution is discussed below. 

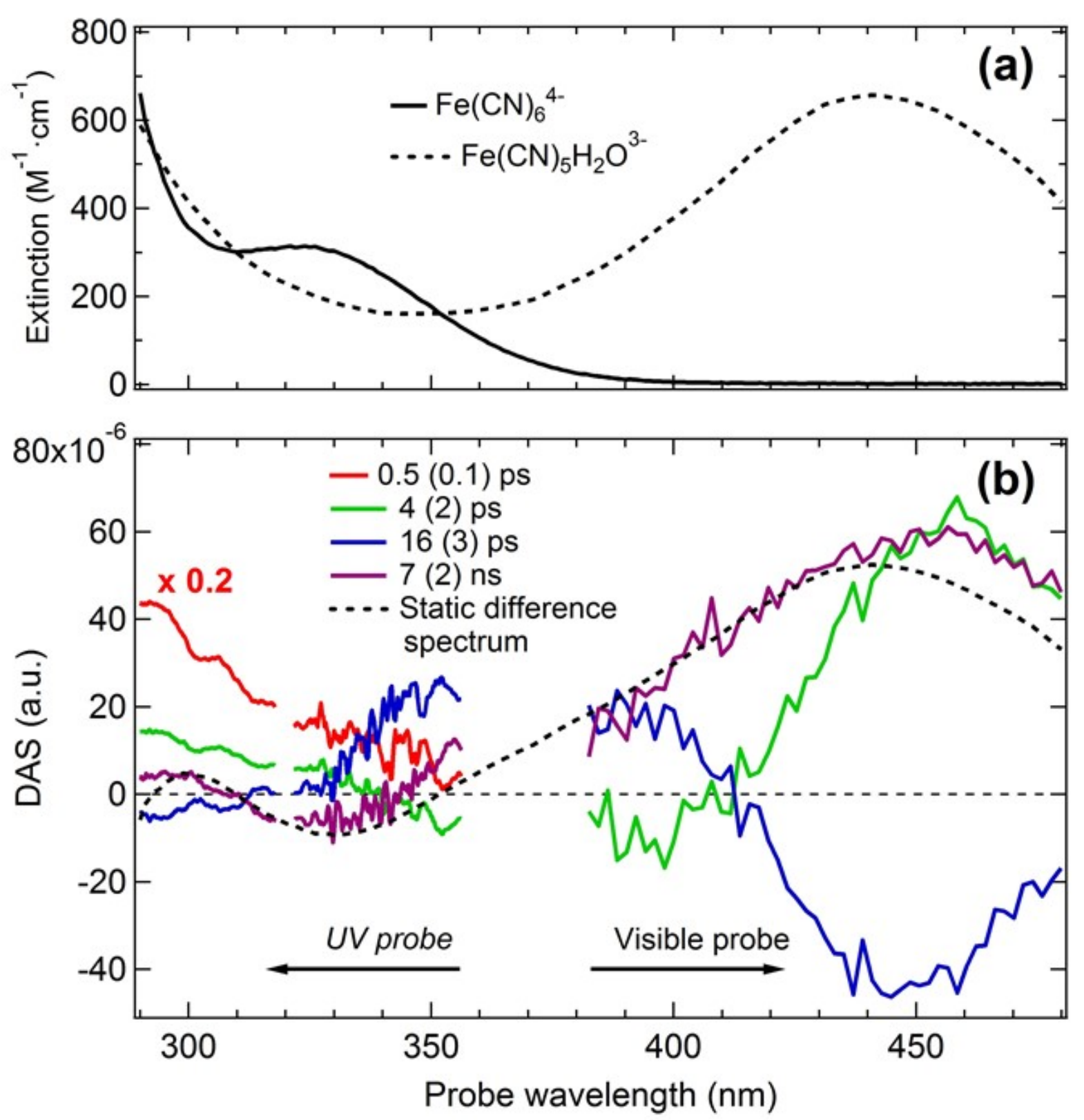

Figure 5. Combined decay associated spectra of aqueous $\left[\mathrm{Fe}(\mathrm{CN})_{6}\right]^{4-}$. (a) Extinction coefficients of aqueous $\left[\mathrm{Fe}(\mathrm{CN})_{6}\right]^{4-}(\mathrm{measured})$ and $\left[\mathrm{Fe}(\mathrm{CN})_{5}\left(\mathrm{H}_{2} \mathrm{O}\right)\right]^{3-} \cdot 62,63$ (b) Decay associated spectra from the 2D UV experiment (probe range $\sim 280-350 \mathrm{~nm}$ ) at $320 \mathrm{~nm}$ pump $(\mathrm{x} 0.1)$ and the white light probe experiment with $323 \mathrm{~nm}$ pump (probe range $\sim 380-480 \mathrm{~nm}$ ). The 0.5 ps component of the $2 \mathrm{D}$ UV data is additionally scaled (x 0.2 ). The static difference spectrum (black dashed line) corresponds to $\varepsilon_{323 \mathrm{~nm}}=0.1 \cdot \varepsilon_{320 \mathrm{~nm}}$. 
We have also estimated quantum yields as a function of excitation wavelength of the $\left[\mathrm{Fe}(\mathrm{CN})_{6}\right]^{3-}, e^{-}$, and $\left[\mathrm{Fe}(\mathrm{CN})_{5}\left(\mathrm{H}_{2} \mathrm{O}\right)\right]^{3-}$ photoproducts. As their extinction coefficients are known, the differences with respect to the $\left[\mathrm{Fe}(\mathrm{CN})_{6}\right]^{4-}$ ground state extinction coefficient can be scaled to match the measured transient difference spectra, and quantum yields can be estimated from the resulting scaling factors. This procedure is described in detail in $\S \mathrm{S} 2$. The extracted quantum yields for photoaquation $\left(\phi_{\mathrm{aq}}\right)$ and photooxidation $\left(\phi_{\mathrm{ox}}\right)$, along with those previously reported, ${ }^{42,43}$ are shown in Fig. 6 and exhibit rather large uncertainties as they involve estimating the fraction of photoexcited molecules $f_{\text {exc }}$, for which we assumed an uncertainty of $100 \%$ to be conservative. However, the observed trends agree with the previously reported values. ${ }^{42,43,47}$

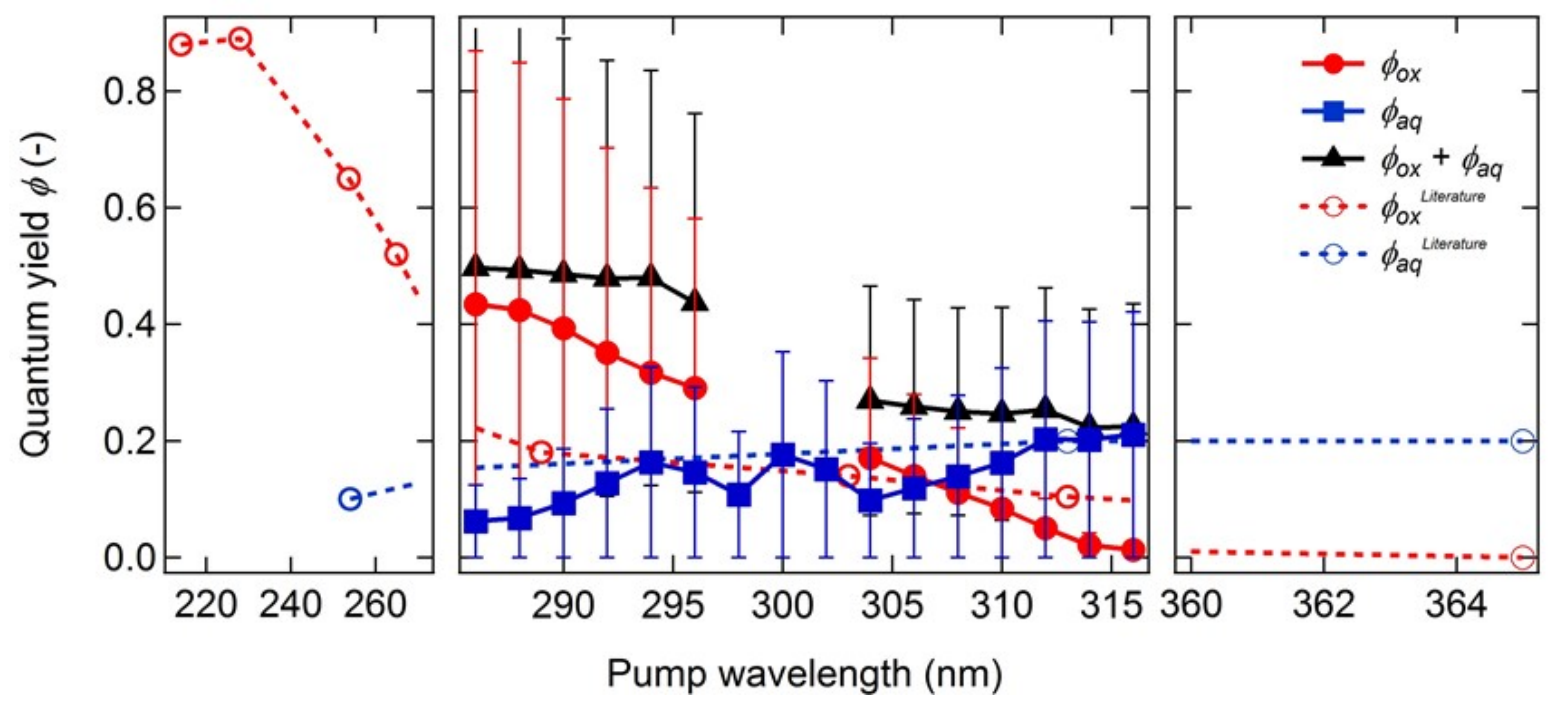

Figure 6. Quantum yields for the production of $\left[\mathrm{Fe}(\mathrm{CN})_{6}\right]^{3-}\left(\phi_{\mathrm{ox}}\right.$, red filled circles $)$ and $\left[\mathrm{Fe}(\mathrm{CN})_{5}\left(\mathrm{H}_{2} \mathrm{O}\right)\right]^{3-}\left(\phi_{\mathrm{aq}}\right.$, blue filled squares $)$, estimated from the $\sim 7 \mathrm{~ns}$ DADAS (Figure S7(vii)) assuming no other contributing processes. $\phi_{\mathrm{ox}}$ is taken as proportional to the action spectrum at $\lambda_{\text {probe }}=300 \mathrm{~nm}$, where the photoaquation difference signal is approximately zero. For each $\lambda_{\text {pump }}$ the static photooxidation spectrum scaled at $\lambda_{\text {probe }}=300 \mathrm{~nm}$ is subtracted from the respective $1 \mathrm{D}$ DAS and $\phi_{\mathrm{aq}}$ is taken as proportional to the action spectrum of the resulting $2 \mathrm{D}$ dataset at $\lambda_{\text {probe }}=320 \mathrm{~nm}$. Literature values for the quantum yields of the photooxidation ${ }^{42}($ at $\mathrm{pH}=6.5)$ and photoaquation ${ }^{43}$ $(\mathrm{pH}=9)$ processes are shown as red and blue dashed lines respectively. 
From Figure 6, we can draw the following conclusions: First, $\phi_{\text {aq }}$ shows no wavelength dependence between $360 \mathrm{~nm}$ and $310 \mathrm{~nm}$, pointing to a Kasha-type behaviour for this photochemical channel, i.e. internal conversion processes lead to a relaxation to the lowest-energy state(s) that is (are) the doorway to the aquation reaction; Second, $\phi_{\mathrm{aq}}$ decreases from $\sim 20 \%$ to $\sim 10 \%$ between $310 \mathrm{~nm}$ and $250 \mathrm{~nm}$. This can be explained by the fact that $\phi_{\mathrm{ox}}$ increases with increasing energy in this same range; Third, the total yield $\left(\phi_{\mathrm{aq}}+\phi_{\mathrm{ox}}\right)$ also increases with increasing excitation energy, pointing to the increased photochemical decomposition via photooxidation with increasing excitation energy. Last, $\left(\phi_{\mathrm{aq}}+\phi_{\mathrm{ox}}\right)<1$ (typically $\sim 0.5$ at $285 \mathrm{~nm}$ and $\sim 0.2$ at $310 \mathrm{~nm}$ ), suggesting that, either not all molecules are decomposed, or that a substantial part reform.

Although photoaquation is observed when we directly excite the lowest lying singlet state ${ }^{1} \mathrm{~T}_{1 \mathrm{~g}}$, the intermediate states leading to $\left[\mathrm{Fe}(\mathrm{CN})_{5}\left(\mathrm{H}_{2} \mathrm{O}\right)\right]^{3-}$ remain unidentified. In order to complement the above analysis, we also carried out TRIR spectroscopy exciting at $320 \mathrm{~nm}$, i.e. into the ${ }^{1} \mathrm{~T}_{1 \mathrm{~g}}$ state.

Figure 7 shows the TRIR transient spectra for $\left[\mathrm{Fe}(\mathrm{CN})_{6}\right]^{4-}$ in $\mathrm{H}_{2} \mathrm{O}$. The corresponding kinetic traces are shown Figures S8 and additional transient spectra for $\mathrm{H}_{2} \mathrm{O}$ are compared in Figure $\mathrm{S} 9$ with those for $\mathrm{D}_{2} \mathrm{O}$. The spectra appear similar for $\mathrm{H}_{2} \mathrm{O}$ and $\mathrm{D}_{2} \mathrm{O}$, and they contain more spectral features than those obtained following $266 \mathrm{~nm}$ excitation. A very weak band due to $\left[\mathrm{Fe}(\mathrm{CN})_{6}\right]^{3-}$ appears at 2117 $\mathrm{cm}^{-1}$ (inset in Figure 7). This is consistent with the 2D UV TA results (Figures 3(c), 5 and 6), which show a weak contribution of photoionization at $320 \mathrm{~nm}$.

From the earliest times, Fig. 7 shows a depletion near the parent band at $2038 \mathrm{~cm}^{-1}$ along with a broad absorption band at $c a$. $2060-2090 \mathrm{~cm}^{-1}$. The latter decays rapidly $\left(\tau_{1}<1 \mathrm{ps}\right)$, concomitant with a partial recovery of the parent band (Figures S8(a) and (c)). The initial recovery corresponds to about $\sim 40 \%$ of the excited molecules and it can tentatively be assigned to geminate recombination of the $\mathrm{CN}^{-}$ radical with the pentacoordinated species formed by irradiation at $320 \mathrm{~nm}$. The IR absorption bands of the aqueous cyanide ion have been reported at $2079 \mathrm{~cm}^{-1}$ with a bandwidth of $16-18 \mathrm{~cm}^{-1}$. Therefore, the $2060-2090 \mathrm{~cm}^{-1}$ band must contain other contributions, as will be seen later. Under $320 \mathrm{~nm}$ excitation, the TRIR spectrum obtained 2 ps after photolysis shows absorption bands near $2060 \mathrm{~cm}^{-1}$ 
and $2090 \mathrm{~cm}^{-1}$ (Figure 7). The $2060 \mathrm{~cm}^{-1}$ band is clearly distinguishable from the initial 2060-2090 $\mathrm{cm}^{-1}$ signal at early times as it grows in $\tau_{2}=4 \pm 2$ ps and decays in $\tau_{3}=23 \pm 4$ ps (Figure S8 (c)), giving rise to a new band at $2049 \mathrm{~cm}^{-1}$ that grows on a similar time scale (19 $\pm 4 \mathrm{ps,} \mathrm{Figure} \mathrm{S} 8(\mathrm{~b})$ ). It partially overlaps the parent bleach band. The $2049 \mathrm{~cm}^{-1}$ band is the IR band of the photoaquated species. ${ }^{66}$ The parent bleach band exhibits an additional recovery in $23 \pm 4$ ps (Figure S8(a)). A similar behaviour is observed in $\mathrm{D}_{2} \mathrm{O}$.

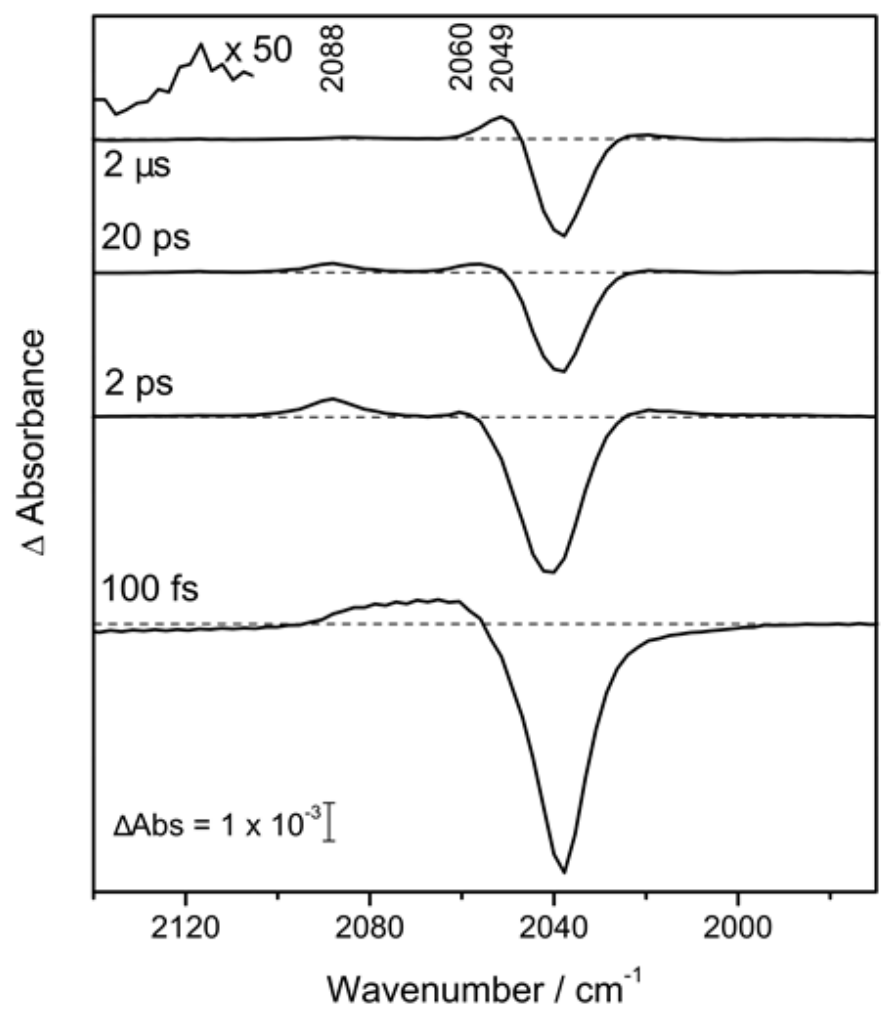

Figure 7. TRIR spectra of $18 \mathrm{mM}\left[\mathrm{Fe}(\mathrm{CN})_{6}\right]^{4-}$ acquired in $\mathrm{H}_{2} \mathrm{O}$ at several time-delays after photolysis at $320 \mathrm{~nm}$. The inset shows the expanded region of the $2117 \mathrm{~cm}^{-1}$ ferricyanide stretch.

The assignment of the $2060 \mathrm{~cm}^{-1}$ and the $\sim 2090 \mathrm{~cm}^{-1}$ bands is now discussed. Close inspection of the profile of the $\sim 2090 \mathrm{~cm}^{-1}$ band shows that it is composed of more than one contribution (Figure S10): a) its width is significantly broader than the spectral resolution of the instrument (ca. $\left.1.5 \mathrm{~cm}^{-1}\right)$; b) there 
are clear shoulders on its high- and low-energy wings; c) the kinetic traces at the wings (Figures S8d and $\mathrm{f}$ ) and at the maximum of the band (Figure S8e) confirm its composite nature. At $2088 \mathrm{~cm}^{-1}$ the intensity decays in $\tau_{3}=23 \pm 4 \mathrm{ps}$, at $2090 \mathrm{~cm}^{-1}$ it grows in $\tau_{2}=4 \pm 2 \mathrm{ps}$ and decays in $\tau_{3}=23 \pm 4 \mathrm{ps}$. At $\leq 2086 \mathrm{~cm}^{-1}$, it first rapidly decays, likely due to overlap with the broad $\mathrm{CN}^{-}$band at early times, and then undergoes a longer decay in $23 \pm 4$ ps. These various trends are further confirmed by the SVD analysis ( $\S \mathrm{S} 5$ ) of the data set in $\mathrm{H}_{2} \mathrm{O}$, which provides the decay associated spectra (DAS) plotted in Figure 8. Four time components emerge from this analysis: i) The $\tau_{1}=0.5$ ps DAS reflects quite well the early time transient observed in Figures 7 and S8, with the bleach band at $2038 \mathrm{~cm}^{-1}$ having a long tail to the red, and the broad positive band in the $2055-2090 \mathrm{~cm}^{-1}$ range; ii) The $\tau_{2}=3.5$ ps DAS shows, along with the bleach band, weak positive features around $2020-2030 \mathrm{~cm}^{-1}$ and a negative one at $\sim 2090$ $\mathrm{cm}^{-1}$. The long blue tail of the bleach may be a rising component of the band that appears at $2060 \mathrm{~cm}^{-1}$ in the 23 ps DAS and also contains a partial rise of the band characteristic for the aquated species (see below); iii) The $\tau_{3}=23$ ps DAS shows two new positive features at 2060 and $\sim 2090 \mathrm{~cm}^{-1}$. The distinction between the different bands making up the latter (Figure S10) is no longer as clear as seen in the time traces in Figure S8. However, all decay with $\tau_{3}$, which is consistent with the corresponding DAS. Finally, the DAS at infinite time exhibits three positive features: weak ones around $2026 \mathrm{~cm}^{-1}$ and at $2088 \mathrm{~cm}^{-1}$ and a prominent one at $\sim 2050 \mathrm{~cm}^{-1}$. All three are characteristic of the aquated form as discussed below (Table 1).

Under $266 \mathrm{~nm}$ excitation, the $\sim 2090 \mathrm{~cm}^{-1}$ band was significantly weaker and any subsequently formed species was not clear. However, spectral fitting of the parent bleach is consistent with formation of a band at $2049 \mathrm{~cm}^{-1}$, which is formed at a similar rate to the decay of the $2090 \mathrm{~cm}^{-1}$ species. Therefore, the TRIR results support photoaquation for both 266 and $320 \mathrm{~nm}$ excitation, but the quantum yield for the former is lower, consistent with the 2D-UV TA experiments. Most importantly, at both pump wavelengths, the various IR features exhibit kinetic behaviours that parallel those reported in the 2D UV and the visible TA spectra. Therefore in Table 1, we have grouped these bands according to their time scales, and we discuss their assignment below. 


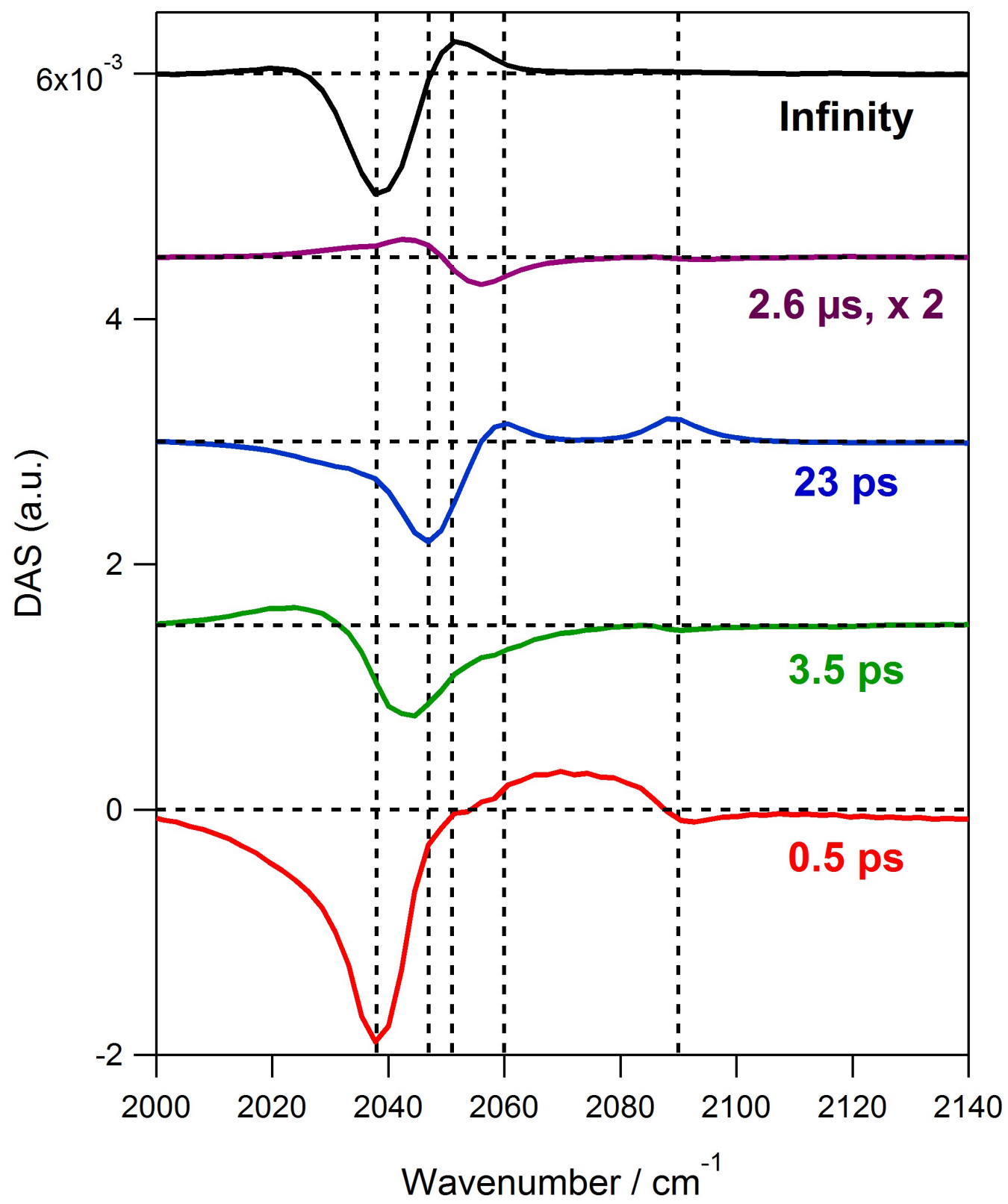


Figure 8. Top: transient spectra at different time delays. Bottom: Decay associated spectra (DAS) obtained from the singular value decomposition of the transient IR data sets in $\mathrm{H}_{2} \mathrm{O}\left(\tau_{1}=0.5 \mathrm{ps}, \tau_{2}=3.5 \mathrm{ps}, \tau_{3}=23 \mathrm{ps}, \tau_{4}=\right.$ infinity $)$.

In order to aid the latter, we performed calculations of the electronic and vibrational energies using density functional theory (DFT, see $\S \mathrm{S} 6$ ). We first calculate the $v_{\mathrm{CN}}$ vibrational frequencies and structural parameters of the hexacoordinated complexes with an explicit unconstrained water solvent model (Figure S11), which is supported by previously published calculations of the spin-state energetics of $\left[\mathrm{Fe}\left(\mathrm{H}_{2} \mathrm{O}\right)_{6}\right]^{3+}$ using a similar approach. ${ }^{67}$ For the $\left[\mathrm{Fe}(\mathrm{CN})_{6}\right]^{4-}$ complex in its ground state, the calculations give a frequency of $2040 \mathrm{~cm}^{-1}$ for the $v_{\mathrm{CN}}$ band (Table S2), consistent with our experimental value of $2038 \mathrm{~cm}^{-1}$. For the $\mathrm{T}_{1}$ state of the complex, calculations predict bands at 2058 , 2067 and $2079 \mathrm{~cm}^{-1}$, with the first and last being the most intense ones. The calculated structure for this state in water shows a significant distortion: a large elongation (by about 20\%) of the axial Fe-C bond (Table S3), found to be $2.40 \AA$ compared to $1.92 \AA$ in the ground state, while the equatorial bond lengths are 1.95 and $2.00 \AA$ in the triplet state. The molecular orbitals (MOs) show that formation of the $\mathrm{T}_{1}$ state involves the population of an antibonding $\mathrm{dz}^{2}$-like orbital (Figures S12 and S13) and, consistent with the calculated axial elongation, this is expected to induce a Jahn-Teller distortion. The elongation of the axial Fe-C bonds is significantly larger than what was measured for Fe(II)polypyridine complexes in their quintet states, ${ }^{68}$ however, it is consistent with optimized triplet state calculations of $\mathrm{Ru}(\mathrm{II})$-polypyridines.[please cite: Alary et al., Inorg. Chem. 47, (2008) 5259, doi: $10.1021 / \mathrm{ic} 800246 \mathrm{t}]$ For example, two opposing $\mathrm{Ru}-\mathrm{N}$ bonds of $[\mathrm{Ru}(\operatorname{tap})]^{2+}(\operatorname{tap}=1-4-5-8-$ tetraazaphenanthrene) have been calculated to elongate from $2.104 \AA$ in the ground state to $2.516 \AA$ in the triplet ligand field state. Indeed, several computational studies on the photodissociation of Ru(II)polypyridines have noted the dissociative nature of ${ }^{3} \mathrm{LF}$ states involving the population of orbitals with a high degree of $\sigma$-antibonding character between the axial $\mathrm{CN}$ ligands and the metal. ${ }^{69,70}$ Our DFT calculations find the excitation energy for the lowest triplet state to be $2.86 \mathrm{eV}$, which is lower in energy than the predicted lowest quintet state (4.66 eV above the ground state), suggesting that it is less likely to be formed (Table S4). 
Next, we consider the pentacoordinated complex: DFT geometry optimization and frequency calculations have been performed in vacuo and with a polarized continuum model (C-PCM) of the solvent for a range of possible pentacoordinated intermediates. The results are summarized in Table S5. The calculations with or without solvent predict a similar energy hierarchy of states: the triplet trigonal bipyramidal $\left({ }^{3} \mathrm{TBP}\right)$ structure being the lowest energy form, followed by the singlet square pyramidal $\left({ }^{1} \mathrm{SP}\right)$, and the triplet square pyramidal $\left({ }^{3} \mathrm{SP}\right)$. We note that the prediction of accurate singlet-triplet splittings is a challenging problem and can be sensitive to the nature of the exchange-correlation functional. ${ }^{71}$ Calculations using the B3LYP* functional, which is parameterized with this in mind, ${ }^{72}$ lead to a lowering of the singlet state energy, bringing the ${ }^{1} \mathrm{SP}$ structure within $2 \mathrm{~kJ} / \mathrm{mol}$ of the ${ }^{3} \mathrm{TBP}$ configuration. Furthermore, the calculated C-PCM frequencies for the ${ }^{3} \mathrm{TBP}$ form shows two strong bands separated by over $20 \mathrm{~cm}^{-1}$, consistent with the 23 ps-lived 2060 and $2090 \mathrm{~cm}^{-1}$ bands observed in the experiment, although the calculated frequencies are somewhat higher. The singlet spin square pyramidal structure has two bands split by less than $10 \mathrm{~cm}^{-1}$.

\section{Discussion}

\section{Assignment of bands:}

We first identify the IR bands. Under $266 \mathrm{~nm}$ excitation and as stated above, the $2117 \mathrm{~cm}^{-1}$ band is due to the oxidised product $\left[\mathrm{Fe}(\mathrm{CN})_{6}\right]^{3-}$, formed within the time-resolution of our experiments. This band partially decays on the timescale of tens of nanoseconds due to recombination with the photo-produced solvated electron (Figure S3(b)). Under $320 \mathrm{~nm}$ excitation, some of the formed IR features are also easily identifiable, such as: the $\left[\mathrm{Fe}(\mathrm{CN})_{6}\right]^{3-} 2117 \mathrm{~cm}^{-1}$ band ${ }^{46}$ and the photoaquated species $\left[\mathrm{Fe}(\mathrm{CN})_{5}\left(\mathrm{H}_{2} \mathrm{O}\right)\right]^{3-}$ band at $2049 \mathrm{~cm}^{-1}$ (reported at $2043 \pm 10 \mathrm{~cm}^{-1}$ in ref. ${ }^{66}$, Table S2). In addition to the latter band, the DAS also revealed the weaker bands at ca. $2026 \mathrm{~cm}^{-1}$ and $2088 \mathrm{~cm}^{-1}$ that belong to the aquated species. The calculations indeed predict two weaker bands at 2037 and $2068 \mathrm{~cm}^{-}$ 1, which we believe are associated to the former two (Table S2). 
The broad $<1$ ps IR band that appears in the $2060-2090 \mathrm{~cm}^{-1}$ region cannot be fully assigned to the $\mathrm{CN}^{-}$ion (in a singlet $\mathrm{X}^{1} \Sigma^{+}$state, Table S2). ${ }^{65}$ Since the ${ }^{3}\left[\mathrm{Fe}(\mathrm{CN})_{6}\right]^{4-}$ complex also absorbs in the same region according to the calculations (Table S2), we conclude that both ${ }^{3}\left[\mathrm{Fe}(\mathrm{CN})_{6}\right]^{4-}$ and $\mathrm{CN}^{-}$ species are observed within the time resolution of the experiment. This early-time IR absorption decays, concomitantly with the partial early time recovery of the parent. It is related to the $\tau_{1}=0.5 \mathrm{ps}$ process that appears in the UV (Figures 5 and S7) with maximum absorption $<280 \mathrm{~nm}$, which we assign to the $\left[\mathrm{Fe}(\mathrm{CN})_{5}\right]^{3-}$ fragment, as the $\mathrm{CN}^{-}$fragment has no known bands in this region. The initial sub-ps decay of these IR and UV bands reflects the transient lifetime of the ${ }^{3}\left[\mathrm{Fe}(\mathrm{CN})_{6}\right]^{4-}$ state and the geminate recombination of $\left[\mathrm{Fe}(\mathrm{CN})_{5}\right]^{3-}$ with $\mathrm{CN}^{-}$. Just as for the IR, the $\mathrm{UV}$ and visible transitions belonging to $\left[\mathrm{Fe}(\mathrm{CN})_{6}\right]^{4-},\left[\mathrm{Fe}(\mathrm{CN})_{6}\right]^{3-}$ and $\left[\mathrm{Fe}(\mathrm{CN})_{5}\left(\mathrm{H}_{2} \mathrm{O}\right)\right]^{3-}$ are easily identifiable and Table 1 shows the assignments of all bands to the involved species and their lifetimes. Note that for the pentacoordinated complex, the predicted frequencies are higher than the experimental ones but lie within the expected level of accuracy for an open-shell transition metal complex, and given the approximate nature of the solvent model.

\section{Mechanism of photoaquation:}

From the body of ultrafast studies on electronically excited metal complexes, ${ }^{73-75}$ electronicvibrational relaxation proceeds at extremely fast time scales of a few tens of fs, to reach the lowest electronically excited state, in line with the Kasha rule. This also applies to chemical reactions. Indeed, the constant photoaquation yield for excitation wavelengths between 310 and $365 \mathrm{~nm}$ reflects this behaviour (the red most wavelength corresponds to the absorption threshold). It is therefore reasonable to assume that the relaxation cascade reaches the lowest triplet state prior to proceeding to dissociation. In addition, $\phi_{\mathrm{aq}}+\phi_{\mathrm{ox}} \leq 0.5$ down to $260 \mathrm{~nm}$ excitation (Figure 7), which implies that there is a substantial recovery of ground state $\left[\mathrm{Fe}(\mathrm{CN})_{6}\right]^{4-}$ on an ultrafast time scale.

Photoexcitation at $320 \mathrm{~nm}$ into the ${ }^{1} \mathrm{~T}_{\mathrm{g}}$ state is followed by Jahn-Teller distortion, due to the degeneracy of the excited state electronic configuration, and ISC into the lower triplet ${ }^{3} \mathrm{~T}_{1 \mathrm{~g}}$ states, 
leading to dissociation of the molecule into $\left[\mathrm{Fe}(\mathrm{CN})_{5}\right]^{3-}$ and $\mathrm{CN}^{-}$. As explained above, the triplet state is characterized by the transfer of one electron from the bonding $t_{2 g}$ orbital to the antibonding $e_{g}$ orbital (Figure S12), and a loosening of the Fe-CN bonds (Table S3), which may favor dissociation.

Therefore, given that from the earliest probed times in our experiments, we have formed an $\left[\mathrm{Fe}(\mathrm{CN})_{5}\right]^{3-}$ species, the subsequent UV, visible and IR spectral changes reflect electronic/structural relaxation of this species. The $\mathrm{CN}^{-}$ion is in a singlet state, and we assume that dissociation proceeds via a triplet state producing the nascent $\left[\mathrm{Fe}(\mathrm{CN})_{5}\right]^{3-}$ in a triplet state, which can adopt either a trigonal bipyramidal (TBP) or a square pyramidal (SP) form. Furthermore, as described above (Table S5), the energies of the calculated states follow the order ${ }^{3} \mathrm{TBP}<{ }^{1} \mathrm{SP}<{ }^{3} \mathrm{SP}$ and the ${ }^{3} \mathrm{SP}$ form $(52 \mathrm{~kJ} / \mathrm{mol}$ higher than ${ }^{3}$ TBP) is the most likely to be generated by dissociation and can undergo a further rearrangement process. $\tau_{2}$ is reflected in a 3.5-4 ps rise of the bands at 2090 and $2060 \mathrm{~cm}^{-1}$ and the decay of the 2086 $\mathrm{cm}^{-1}$ band (Figure 8 and $\mathrm{S} 8(\mathrm{~d})$ ) and corresponds to the production of ${ }^{3} \mathrm{TBP}$. This process can either be associated to the ${ }^{3} \mathrm{SP}$ form undergoing a conformational change to the ${ }^{3} \mathrm{TBP}$ form, or a spin and conformational relaxation which would include a passage via the intermediate ${ }^{1} \mathrm{SP}$ form, where both SP species are predicted to exhibit two bands. The involvement of a singlet $\left[\mathrm{Fe}(\mathrm{CN})_{5}\right]^{3-}$ moiety in the kinetic processes on the 4-20 ps timescale is very unlikely as similar singlet 16-electron intermediates have been shown to coordinate to very weakly coordinating solvents on the femtosecond timescale e.g. $\mathrm{Cr}(\mathrm{CO})_{5}$ in alkane.$^{76} \mathrm{H}_{2} \mathrm{O}$ is a much more coordinating solvent to such fragments than alkanes and it is expected to react on faster timescales. This is further discussed below.

For the ${ }^{3}$ TBP form, we have seen that the calculations predict two bands separated by ca. $20 \mathrm{~cm}^{-}$ ${ }^{1}$ with an intensity ratio of $\sim 3: 1$ between the lower and higher energy bands. This trend is reproduced between the $2060 \mathrm{~cm}^{-1}$ and $2090 \mathrm{~cm}^{-1}$ bands, which in addition grow and decay on the same time scales (Figures S8(c) and S8(f)). This leads us to associate the 20-25 ps timescale of $\tau_{3}$ to the decay of the ${ }^{3}$ TBP complex. Because this is also the timescale for formation of the aquated species, we consider that formation of the latter proceeds from a ${ }^{3} \mathrm{TBP}$ precursor. 
The rise-time $\left(3.5-4 \mathrm{ps}, \tau_{2}\right)$ and decay $\left(23 \mathrm{ps}, \tau_{3}\right)$ of the $2090 \mathrm{~cm}^{-1}$ and $2060 \mathrm{~cm}^{-1}$ bands are similar to those of the band in the 330 to $410 \mathrm{~nm}$ region and likewise, the decay time corresponds to the rise of the aquated complex. This, along with the fact that the 4 ps and 16 ps $\mathrm{UV}$-visible bands are clearly correlated (Figure 5) suggests that we are still dealing with the $\left[\mathrm{Fe}(\mathrm{CN})_{5}\right]^{3-}$ intermediate, consistent with the SP to TBP rearrangement.

Concomitant with the decay of the final $\left[\mathrm{Fe}(\mathrm{CN})_{5}\right]^{3-}$ species, the aquated $\left[\mathrm{Fe}(\mathrm{CN})_{5}\left(\mathrm{H}_{2} \mathrm{O}\right)\right]^{3-}$ (at $2049 \mathrm{~cm}^{-1}$ in the IR and ca. $440 \mathrm{~nm}$ in the UV) grows in $23 \mathrm{ps}$. This is surprisingly slow for solvation of a 16-electron intermediate in a strongly coordinating solvent like water. For example, solvation by alkane solvents of $\mathrm{Cr}(\mathrm{CO})_{5}$ formed by photoejection of $\mathrm{CO}$ from $\mathrm{Cr}(\mathrm{CO})_{6}$ occurs in $<1 \mathrm{ps}^{76}{ }^{7}$ Similar behaviour is observed for many metal carbonyl species in these weakly coordinating solvents. ${ }^{16,77}$ Photolysis of $\mathrm{Fe}(\mathrm{CO})_{5}$ in the condensed phase produces ${ }^{1} \mathrm{Fe}(\mathrm{CO})_{4},{ }^{13,26}$ which rapidly converts to ${ }^{3} \mathrm{Fe}(\mathrm{CO})_{4}$ before subsequent reaction with solvent species, which is very slow and strongly dependent on the nature of the solvent (ranging from 43 ps in $\mathrm{EtOH}^{21}$ to $13 \mathrm{~ns}$ in heptane ${ }^{23}$ ). This scenario is very similar to the one proposed above where we are dealing with a triplet state species and the spin-change required to produce the final photoproduct decreases the rate of this process by two orders of magnitude compared to an unsaturated singlet metal carbonyl species. ${ }^{26,76}$ The recovery of $\left[\mathrm{Fe}(\mathrm{CN})_{6}\right]^{4-}$ occurs on all the above time constants: at the earliest times $(<1 \mathrm{ps})$, geminate recombination takes places concomitant with the disappearance of the broad IR absorption. This early recombination amounts to $\sim 40 \%$ of the initially bleached molecules. The 3-4 ps time constant of the parent bleach recovery reflects that already in the SP form some recombination to $\mathrm{CN}^{-}$fragments is occurring. We consider this to be a geminate recombination, given its short time scale. Finally, further recombination occurs over $\sim 20$ ps, reaching $\sim 25 \%$ of the initially depleted molecules. This time scale is similar to that for photoaquation and therefore we conclude that the latter is the rate-determining step for the nongeminate recombination of $\left[\mathrm{Fe}(\mathrm{CN})_{5}\right]^{3-}$ and $\mathrm{CN}^{-}$species (there are more water molecules than $\mathrm{CN}^{-}$ fragments in the environment of the pentacoordinated species). The fact that no clear bands attributed 
to $\mathrm{CN}$ appear at longer times may suggest that the broad IR absorption is predominantly due to ${ }^{3}\left[\mathrm{Fe}(\mathrm{CN})_{6}\right]^{4-}$ (Table S2).

Based on the above, we propose the following scenario for the photoaquation process, as summarized in Scheme 1: (i) Photoexcitation at $320 \mathrm{~nm}$ into the ${ }^{1} \mathrm{~T}_{1 \mathrm{~g}}$ state generates a triplet state of $\left[\mathrm{Fe}(\mathrm{CN})_{6}\right]^{4-}$ within the time-resolution of our experiments. DFT predicts a lengthening of the Fe-C axial bonds in this state (Table S3); (ii) This favors or leads to dissociation of the molecule and leads to the appearance of the $\left[\mathrm{Fe}(\mathrm{CN})_{5}\right]^{3-}$ fragment in the triplet SP form; (iii) Immediately after dissociation, partial geminate recombination of $\mathrm{CN}^{-}$takes place with the SP $\left[\mathrm{Fe}(\mathrm{CN})_{5}\right]^{3-}$ species $\left(\tau_{1}\right)$; (iv) the remaining pentacoordinated fragments undergo structural rearrangement the more stable ${ }^{3} \mathrm{TBP}$ form in 3-4 ps. We propose that at this stage, water molecules start to move in and compete with the remaining $\mathrm{CN}^{-}$anions for bond formation (see Table 1 and Figure S8(b)) $\left(\tau_{2}\right)$; (v) The process of aquation ( $\sim 20 \mathrm{ps,}$ $\tau_{2}$ ) is then slowed down by the spin change required to form the final product and due to steric constraints imposed by the TBP geometry of the intermediate and its reorganization.

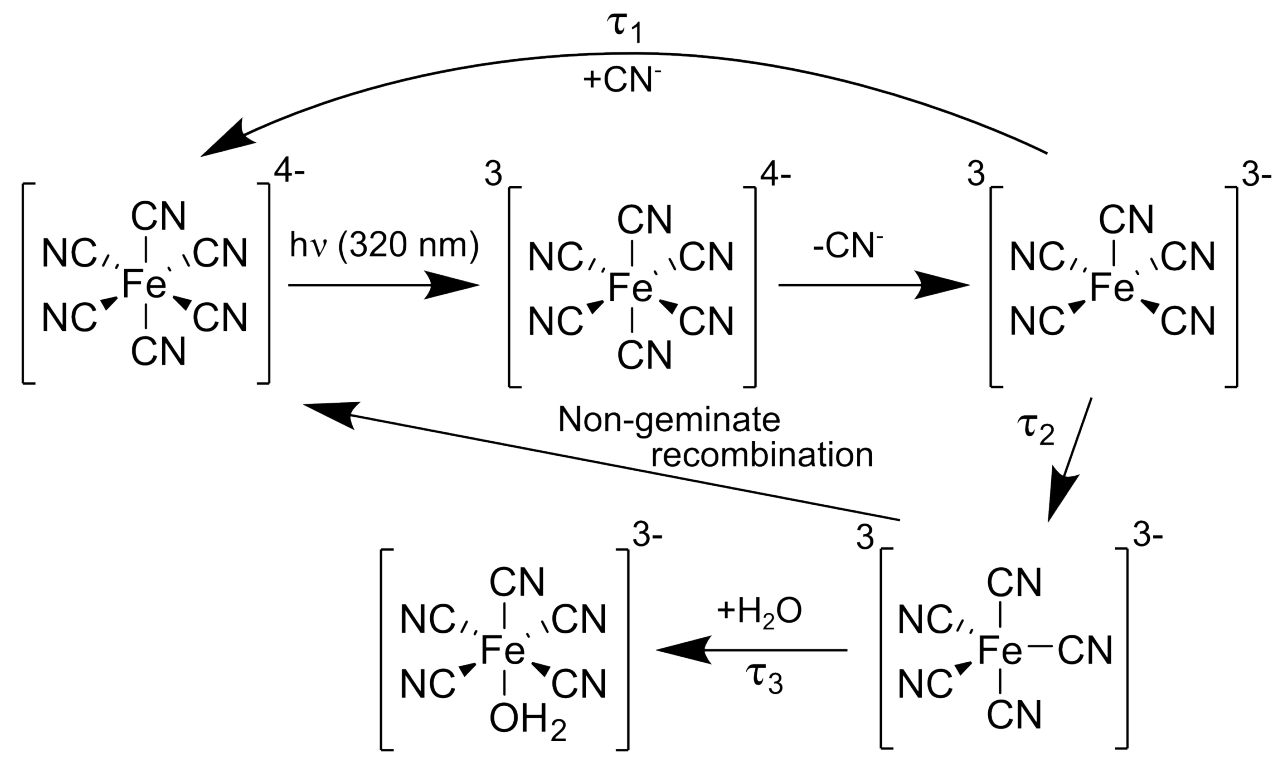

Scheme 1 : The proposed steps involved in the photoaquation of $\left[\mathrm{Fe}(\mathrm{CN})_{6}\right]^{4-}$ after $320 \mathrm{~nm}$ absorption in $\mathrm{H}_{2} \mathrm{O}$. 
While it seems intuitive that the system dissociates in a SP form, which does not impose steric constraints to the uptake of a water molecule, the binding of the latter by the TBP complex is less trivial as it supposes some rearrangement back to the square pyramidal form in order to accommodate the water molecule. Surely the participation of the water molecule is needed in order to make this rearrangement possible. Molecular dynamics simulations are needed to further elucidate the details of the water binding. This being said, the present observations invalidate the mechanism of dissociative interchange between $\left[\mathrm{Fe}(\mathrm{CN})_{6}\right]^{4-}$ and $\mathrm{H}_{2} \mathrm{O}$ proposed by Finston and Drickamer. ${ }^{54}$

Further evidence for the $\sim 20$ ps time scale process for binding of water being due to reaction with a triplet fragment comes from the fact that it is of the same order to magnitude as that reported for the case of ${ }^{3} \mathrm{Fe}(\mathrm{CO})_{5}$ in methanol, ${ }^{20,21}$ and faster than the corresponding reaction in $n$-heptane, in supercritical xenon and supercritical $\mathrm{CH}_{4},{ }^{23}$ but it is notably different to the cases of singlet reactivity of $\mathrm{Fe}(\mathrm{CO})_{5}$ in ethanol ${ }^{26}$ and $\left[\mathrm{Cr}(\mathrm{CO})_{4}(\mathrm{bpy})\right]$ in methanol. ${ }^{28,30}$ The latter two cases are remarkable in that solvent binding occurs in a few 100s fs, i.e. time scales typical of dissociation, while the solvent molecules are at thermal energies. As mentioned in the introduction, the very short time scale $(\leq 300 \mathrm{fs})$ for solvent substitution in the case of $\mathrm{Fe}(\mathrm{CO})_{5}$ in ethanol ${ }^{26}$ was justified by the existence of an interaction between the solvent molecules and the mother solute based on IR studies and DFT calculations. ${ }^{78}$ It should also be noted that this process pertains only to ${ }^{1} \mathrm{Fe}(\mathrm{CO})_{4}$, while ${ }^{3} \mathrm{Fe}(\mathrm{CO})_{4}$ was found to persist until the end of the experiment, consistent with the much slower rate of solvation found earlier and relevant to our experiments where solvation occurs on a relatively slow timescale because of the required spin and conformational changes. Recent ab initio Car-Parrinello molecular dynamics simulations have so far not supported the ultrafast binding of a solvent molecule in $\mathrm{Fe}(\mathrm{CO})_{5}{ }^{27}$ In the present case, despite indications from $2 \mathrm{D} \mathrm{IR}^{40,55}$ and $\mathrm{x}$-ray studies ${ }^{39,41}$ of a specific interaction of $\left[\mathrm{Fe}(\mathrm{CN})_{6}\right]^{4-}$ with water molecules, the solvent does not seem to play an essential role in the photochemistry of the molecule, except to allow the process of geminate recombination by caging the fragments within the first ps. The lack of an isotope effect on the kinetics of photoaquation is also in 
line with the relatively long time scales of the reported processes which is governed by barrier for conversion of ${ }^{3}\left[\mathrm{Fe}(\mathrm{CN})_{5}\right]^{3-}$ to ${ }^{1}\left[\mathrm{Fe}(\mathrm{CN})_{5}\left(\mathrm{H}_{2} \mathrm{O}\right)\right]^{3-}$.

Other examples of photoaquation reactions of metal cyanides include $\left[\mathrm{Co}(\mathrm{CN})_{6}\right]^{3-}$, which presents an interesting target of investigation as it is isoelectronic to $\left[\mathrm{Fe}(\mathrm{CN})_{6}\right]^{4-} .\left[\mathrm{Co}(\mathrm{CN})_{6}\right]^{3-}$ has not been the subject of any ultrafast time-resolved investigations but early studies based on ligand exchange reactions ${ }^{36}$ and pressure-dependent quantum yield measurements ${ }^{79}$ have pointed toward a dissociative interchange mechanism in the formation of $\left[\mathrm{Co}(\mathrm{CN})_{5}\left(\mathrm{H}_{2} \mathrm{O}\right)\right]^{2-}$. This difference to the ferrocyanide case may be indicative of an increased dissociation energy of the $\mathrm{Co}-\mathrm{CN}$ bond.

Finally, the increased photoionization yield with increasing energy points to a non-Kasha behaviour for this channel, which is logical since electron dynamics are much faster than the nuclear dynamics associated with intramolecular relaxation. This is also reflected in the decrease of the photoaquation quantum yield upon excitation of the CTTS states and consistent with the lack of an ultrafast CTTS fluorescence, which we could not detect. ${ }^{48}$

The body of work on ultrafast intramolecular relaxation of complex molecular systems in solution show that the Kasha Rule is largely verified and exceptions are rare. ${ }^{75,80}$ Intramolecular energy redistribution occurs at extremely short time scales, reaching even values shorter than the high frequency vibrational time scales, ${ }^{73,81}$ while intersystem crossing events also occur at very short time scales. ${ }^{74}$ It is therefore expected that the Kasha Rule will also be verified for photochemical reactions, i.e. the significant chemistry involves only the lowest states. The only reaction channel that competes in any significant way with intramolecular energy redistribution are photooxidation events, as the release of an electron must occur at significantly shorter time scales than the vibrational ones. This is valid for CTTS dynamics, as in the present case, or even interfacial electron injection of a molecular adsorbate on a semiconductor substrate. ${ }^{82-85}$ 


\section{Conclusions}

We have carried out a detailed investigation of the excitation energy-dependent ultrafast photochemistry of aqueous $\left[\mathrm{Fe}(\mathrm{CN})_{6}\right]^{4-}$. Combining advanced ultrafast spectroscopic tools: 2dimensional UV spectroscopy, visible and infrared transient absorption spectroscopy, along with quantum chemical calculations, we have elucidated the photoaquation mechanism of $\left[\mathrm{Fe}(\mathrm{CN})_{6}\right]^{4-}$ in water. The initial events are an ultrafast intramolecular relaxation to the lowest triplet state and dissociation of the molecule with release of a $\mathrm{CN}^{-}$fragment. Part of the fragments recombine geminately within the solvent cage. All these events (intramolecular energy redistribution, dissociation, geminate recombination) occur in $<0.5 \mathrm{ps}$. The subsequent observed dynamics is all due to the $\left[\mathrm{Fe}(\mathrm{CN})_{5}\right]^{3-}$ fragment, which is initially formed in the square pyramidal configuration in the triplet state. It then undergoes conformational changes in 3-4 ps to the lower lying triplet state of the trigonal pyramidal form. Binding of water molecules takes place in $\sim 20 \mathrm{ps}$ and shows no isotope effect. This relatively long time scale must reflect a rearrangement of the pentacoordinated trigonal bipyramidal complex to a geometry favoring uptake of a water molecule. Molecular dynamics simulations will be needed to further support this scenario. In addition, ultrafast $\mathrm{x}$-ray spectroscopy provides ideal tools to detect both the nuclear, electronic and spin structure of the intermediate pentacoordinated form ${ }^{86}$ and studies are on-going at $\mathrm{x}$-ray free electron lasers to this purpose.

\section{Acknowledgements:}

This work was funded by the Swiss NSF via contracts 124520,135502 and 158890 and via the NCCR MUST. We also thank the University of Nottingham and EPSRC for funding.

Table 1. IR, UV and visible bands and their kinetics upon $320 \mathrm{~nm}$ excitation

\begin{tabular}{|l|l|c|}
\hline Vibrational bands in $\mathrm{H}_{2} \mathrm{O}\left(\mathrm{D}_{2} \mathrm{O}\right)$ & Electronic bands in $\mathrm{H}_{2} \mathrm{O}$ & Assignment \\
\hline
\end{tabular}




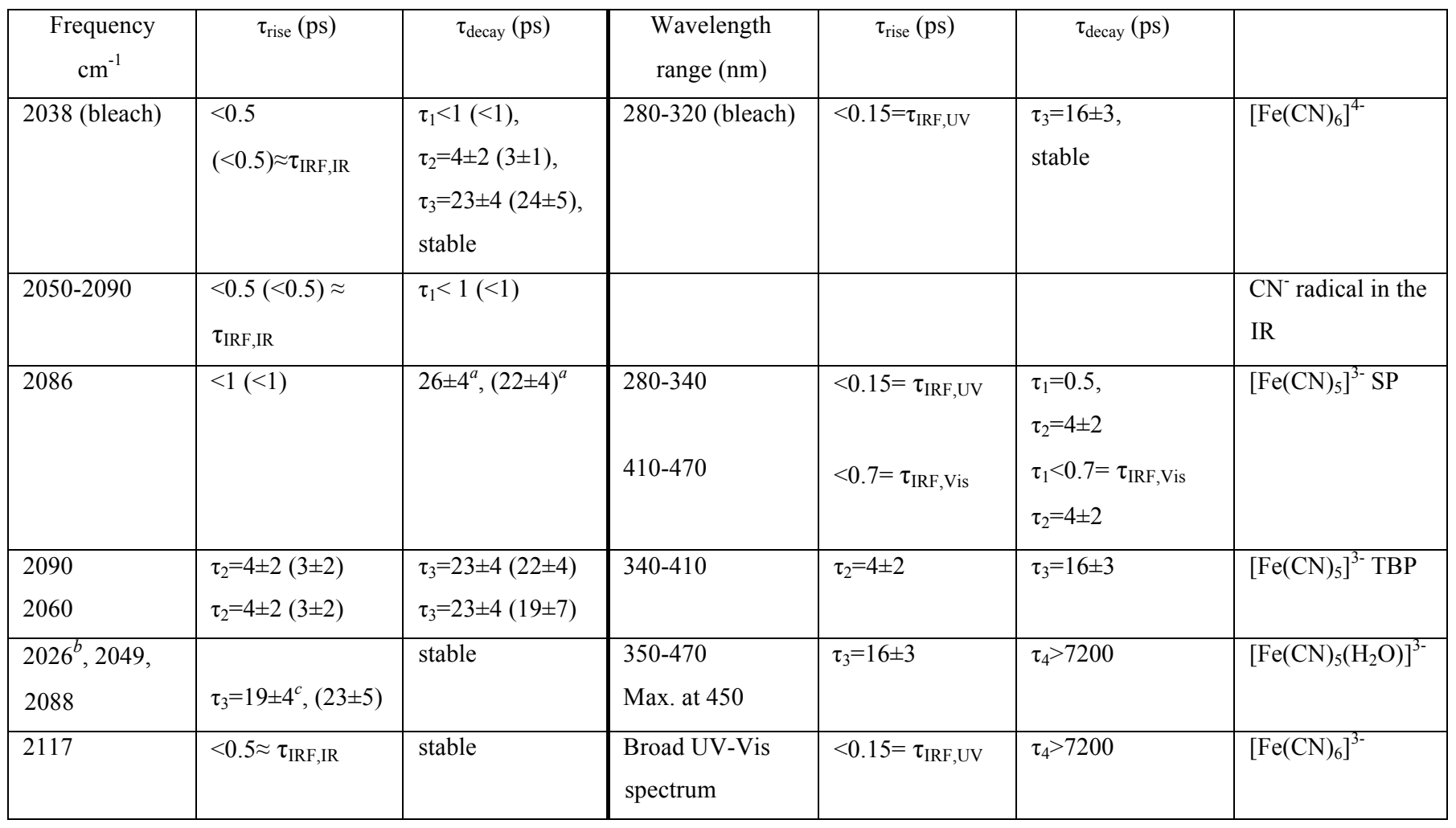

${ }^{a}$ An additional $<1$ ps contribution is observed, which can be attributed to overlap with the $\mathrm{CN}^{-}$band (see Figures 7 and $\mathrm{S} 8$ ). ${ }^{b}$ It is difficult to resolve the experimental band at $2026 \mathrm{~cm}^{-1}$ due to overlap with the parent bleach. The assignment is done on the basis of band-fitting, DFT calculations (Table S2) and previous work. ${ }^{66}{ }^{c} \mathrm{An}$ additional $4 \mathrm{ps}$ transient is observed.

\section{References}


(1) Franck, J.; Rabinowitsch, E. Transactions of the Faraday Society 1934, 30, 120.

(2) Voth, G. A.; Hochstrasser, R. M. J Phys Chem-Us 1996, 100, 13034.

(3) Carpenter, B. K.; Harvey, J. N.; Orr-Ewing, A. J. J Am Chem Soc 2016, 138, 4695.

(4) Schwentner, N.; Bressler, C.; Lawrence, W.; Xu, J.; Chergui, M. Chem Phys 1994, 189, 205.

(5) Schriever, R.; Chergui, M.; Kunz, H.; Stepanenko, V.; Schwentner, N. J Chem Phys 1989, $91,4128$.

(6) Apkarian, V. A.; Schwentner, N. Chem Rev 1999, 99, 1481.

(7) Harris, A. L.; Brown, J. K.; Harris, C. B. Annu Rev Phys Chem 1988, 39, 341.

(8) Fleming, G. R.; vanGrondelle, R. Curr Opin Struc Biol 1997, 7, 738.

(9) Schriever, R.; Chergui, M.; Unal, O.; Schwentner, N.; Stepanenko, V. J Chem Phys 1990, 93, 3245.

(10) Erras-Hanauer, H.; Clark, T.; van Eldik, R. Coordin Chem Rev 2003, 238, 233.

(11) Rotzinger, F. P. Chem Rev 2005, 105, 2003.

(12) Swart, M.; Costas Salgueiro, M. Spin states in biochemistry and inorganic chemistry : influence on structure and reactivity; John Wiley \& Sons, 2015.

(13) Poliakoff, M.; Turner, J. J. Angew Chem Int Edit 2001, 40, 2809.

(14) Simon, J. D.; Xie, X. L. J Phys Chem-Us 1986, 90, 6751.

(15) Joly, A. G.; Nelson, K. A. J Phys Chem-Us 1989, 93, 2876.

(16) Joly, A. G.; Nelson, K. A. Chem Phys 1991, 152, 69.

(17) Simon, J. D.; Xie, X. L. J Phys Chem-Us 1989, 93, 291.

(18) Xie, X. L.; Simon, J. D. J Am Chem Soc 1990, 112, 1130.

(19) Kotz, K. T.; Yang, H.; Snee, P. T.; Payne, C. K.; Harris, C. B. J Organomet Chem 2000, 596, 183.

(20) Snee, P. T.; Payne, C. K.; Kotz, K. T.; Yang, H.; Harris, C. B. J Am Chem Soc 2001, 123, 2255.

(21) Snee, P. T.; Payne, C. K.; Mebane, S. D.; Kotz, K. T.; Harris, C. B. J Am Chem Soc 2001, $123,6909$.

(22) Yang, H.; Snee, P. T.; Kotz, K. T.; Payne, C. K.; Harris, C. B. J Am Chem Soc 2001, 123, 4204.

(23) Portius, P.; Yang, J. X.; Sun, X. Z.; Grills, D. C.; Matousek, P.; Parker, A. W.; Towrie, M.; George, M. W. J Am Chem Soc 2004, 126, 10713.

(24) Besora, M.; Carreon-Macedo, J. L.; Cowan, A. J.; George, M. W.; Harvey, J. N.; Portius, P.; Ronayne, K. L.; Sun, X. Z.; Towrie, M. J Am Chem Soc 2009, 131, 3583.

(25) Ahr, B.; Chollet, M.; Adams, B.; Lunny, E. M.; Laperle, C. M.; Rose-Petruck, C. Phys Chem Chem Phys 2011, 13, 5590. 
(26) Wernet, P.; Kunnus, K.; Josefsson, I.; Rajkovic, I.; Quevedo, W.; Beye, M.; Schreck, S.; Grubel, S.; Scholz, M.; Nordlund, D.; Zhang, W.; Hartsock, R. W.; Schlotter, W. F.; Turner, J. J.; Kennedy, B.; Hennies, F.; de Groot, F. M. F.; Gaffney, K. J.; Techert, S.; Odelius, M.; Fohlisch, A. Nature 2015, 520, 78.

(27) Kunnus, K.; Josefsson, I.; Rajkovic, I.; Schreck, S.; Quevedo, W.; Beye, M.; Weniger, C.; Grübel, S.; Scholz, M.; Nordlund, D.; Zhang, W.; Hartsock, R. W.; Gaffney, K. J.; Schlotter, W. F.; Turner, J. J.; Kennedy, B.; Hennies, F.; de Groot, F. M. F.; Techert, S.; Odelius, M.; Wernet, P.; Föhlisch, A. Structural Dynamics 2016, 3, 043204.

(28) Farrell, I. R.; Matousek, P.; Towrie, M.; Parker, A. W.; Grills, D. C.; George, M. W.; Vlcek, A. Inorg Chem 2002, 41, 4318.

(29) Vichova, J.; Hartl, F.; Vlcek, A. J Am Chem Soc 1992, 114, 10903.

(30) Farrell, I. R.; Matousek, P.; Vlcek, A. J Am Chem Soc 1999, 121, 5296.

(31) Farrell, I. R.; Matousek, P.; Kleverlaan, C. J.; Vlcek, A. Chem-Eur J 2000, 6, 1386.

(32) Farrell, I. R.; Vlcek, A. Coordin Chem Rev 2000, 208, 87.

(33) Tfouni, E.; Krieger, M.; McGarvey, B. R.; Franco, D. W. Coordin Chem Rev 2003, 236, 57.

(34) Liu, Y.; Turner, D. B.; Singh, T. N.; Angeles-Boza, A. M.; Chouai, A.; Dunbar, K. R.; Turro, C. J Am Chem Soc 2009, 131, 26.

(35) Asperger, S. Transactions of the Faraday Society 1952, 48, 617.

(36) Wrighton, M.; Hammond, G. S.; Gray, H. B. J Am Chem Soc 1971, 93, 5254.

(37) MacDiarmid, A. G.; Hall, N. F. J Am Chem Soc 1953, 75, 5204.

(38) MacDiarmid, A. G.; Hall, N. F. J Am Chem Soc 1954, 76, 4222.

(39) Aziz, E. F.; Rittmann-Frank, M. H.; Lange, K. M.; Bonhommeau, S.; Chergui, M. Nat Chem 2010, 2, 853.

(40) Prampolini, G.; Yu, P. Y.; Pizzanelli, S.; Cacelli, I.; Yang, F.; Zhao, J. A.; Wang, J. P. J Phys Chem B 2014, 118, 14899.

(41) Penfold, T. J.; Reinhard, M.; Rittmann-Frank, M. H.; Tavernelli, I.; Rothlisberger, U.; Milne, C. J.; Glatzel, P.; Chergui, M. J Phys Chem A 2014, 118, 9411.

(42) Shirom, M.; Stein, G. J Chem Phys 1971, 55, 3372.

(43) Shirom, M.; Stein, G. J Chem Phys 1971, 55, 3379.

(44) Mialocq, J. C.; Sutton, J.; Goujon, P. Nuovo Cimento B 1981, 63, 317.

(45) Pommeret, S.; Naskrecki, R.; van der Meulen, P.; Menard, M.; Vigneron, G.; Gustavsson, T. Chemical Physics Letters 1998, 288, 833.

(46) Anderson, N. A.; Hang, K.; Asbury, J. B.; Lian, T. Q. Chemical Physics Letters 2000, 329, 386.

(47) Lenchenkov, V.; Kloepfer, J.; Vilchiz, V.; Bradforth, S. E. Chemical Physics Letters 2001, $342,277$. 
(48) Reinhard, M.; Penfold, T. J.; Lima, F. A.; Rittmann, J.; Rittmann-Frank, M. H.; Abela, R.; Tavernelli, I.; Rothlisberger, U.; Milne, C. J.; Chergui, M. Structural Dynamics 2014, 1, 024901.

(49) Messina, F.; Bram, O.; Cannizzo, A.; Chergui, M. Nature Communications 2013, 4, 2119.

(50) Gray, H. B.; Beach, N. A. J Am Chem Soc 1963, 85, 2922.

(51) Toma, H. E.; Batista, A. A.; Gray, H. B. J Am Chem Soc 1982, 104, 7509.

(52) Gaspar, V.; Beck, M. T. Polyhedron 1983, 2, 387.

(53) Bolvin, H. J Phys Chem A 1998, 102, 7525.

(54) Finston, M. I.; Drickamer, H. G. J Phys Chem-Us 1981, 85, 50.

(55) Yu, P. Y.; Yang, F.; Zhao, J.; Wang, J. P. J Phys Chem B 2014, 118, 3104.

(56) Aubock, G.; Consani, C.; Monni, R.; Cannizzo, A.; van Mourik, F.; Chergui, M. Rev Sci Instrum 2012, 83.

(57) Aubock, G.; Consani, C.; van Mourik, F.; Chergui, M. Opt Lett 2012, 37, 2337.

(58) Consani, C.; Aubock, G.; van Mourik, F.; Chergui, M. Science 2013, 339, 1586.

(59) Greetham, G. M.; Burgos, P.; Cao, Q. A.; Clark, I. P.; Codd, P. S.; Farrow, R. C.; George, M. W.; Kogimtzis, M.; Matousek, P.; Parker, A. W.; Pollard, M. R.; Robinson, D. A.; Xin, Z. J.; Towrie, M. Appl Spectrosc 2010, 64, 1311.

(60) Greetham, G. M.; Donaldson, P. M.; Nation, C.; Sazanovich, I. V.; Clark, I. P.; Shaw, D. J.; Parker, A. W.; Towrie, M. App/ Spectrosc 2016, 70, 645.

(61) Chen, X. Y.; Larsen, D. S.; Bradforth, S. E.; van Stokkum, I. H. M. J Phys Chem A 2011, $115,3807$.

(62) Gale, R.; Mccaffer.Aj J Chem Soc Dalton 1973, 1344.

(63) Montenegro, A. C.; Dabrowski, S. G.; Gutierrez, M. M.; Amorebieta, V. T.; Bari, S. E.; Olabe, J. A. Inorg Chim Acta 2011, 374, 447.

(64) Helbing, J.; Bonacina, L.; Pietri, R.; Bredenbeck, J.; Hamm, P.; van Mourik, F.; Chaussard, F.; Gonzalez-Gonzalez, A.; Chergui, M.; Ramos-Alvarez, C.; Ruiz, C.; Lopez-Garriga, J. Biophysical Journal 2004, 87, 1881.

(65) Hamm, P.; Lim, M.; Hochstrasser, R. M. The Journal of chemical physics 1997, 107, 10523.

(66) Herington, E. F. G.; Kynaston, W. J Chem Soc 1955, 3555.

(67) Radon, M.; Gassowska, K.; Szklarzewicz, J.; Broclawik, E. Journal of chemical theory and computation 2016, 12, 1592.

(68) Gawelda, W.; Pham, V. T.; Benfatto, M.; Zaushitsyn, Y.; Kaiser, M.; Grolimund, D.; Johnson, S. L.; Abela, R.; Hauser, A.; Bressler, C.; Chergui, M. Phys Rev Lett 2007, 98, 057401.

(69) Salassa, L.; Garino, C.; Salassa, G.; Gobetto, R.; Nervi, C. J Am Chem Soc 2008, 130, 9590.

(70) Tu, Y.-J.; Mazumder, S.; Endicott, J. F.; Turro, C.; Kodanko, J. J.; Schlegel, H. B. Inorg Chem 2015, 54, 8003. 
(71) Delcey, M. G.; Freitag, L.; Pedersen, T. B.; Aquilante, F.; Lindh, R.; Gonzalez, L. J Chem Phys 2014, 140.

(72) Reiher, M.; Salomon, O.; Hess, B. A. Theor Chem Acc 2001, 107, 48.

(73) Bräm, O.; Messina, F.; El-Zohry, A.; Cannizzo, A.; Chergui, M. Chem Phys 2012, 393, 51.

(74) Aubock, G.; Chergui, M. Nat Chem 2015, 7, 629.

(75) Chergui, M. Accounts Chem Res 2015, 48, 801.

(76) Simon, J. D.; Xie, X. J Phys Chem-Us 1987, 91, 5538.

(77) Dougherty, T.; Heilweil, E. J. Chemical physics letters 1994, 227, 19.

(78) Lee, T.; Benesch, F.; Jiang, Y.; Rose-Petruck, C. G. Chem Phys 2004, 299, 233.

(79) Angermann, K.; van Eldik, R.; Kelm, H.; Wasgestian, F. Inorg Chim Acta 1981, 49, 247.

(80) Chergui, M. Dalton T 2012, 41, 13022.

(81) Messina, F.; Pomarico, E.; Silatani, M.; Baranoff, E.; Chergui, M. The Journal of Physical Chemistry Letters 2015, 4475.

(82) Huber, R.; Moser, J. E.; Gratzel, M.; Wachtveitl, J. J Phys Chem B 2002, 106, 6494.

(83) Schnadt, J.; Bruhwiler, P. A.; Patthey, L.; O'Shea, J. N.; Sodergren, S.; Odelius, M.; Ahuja, R.; Karis, O.; Bassler, M.; Persson, P.; Siegbahn, H.; Lunell, S.; Martensson, N. Nature 2002, 418, 620.

(84) Bram, O.; Cannizzo, A.; Chergui, M. Phys Chem Chem Phys 2012, 14, 7934.

(85) Huber, R.; Dworak, L.; Moser, J. E.; Grätzel, M.; Wachtveitl, J. The Journal of Physical Chemistry C 2016, 120, 8534.

(86) Milne, C. J.; Penfold, T. J.; Chergui, M. Coordin Chem Rev 2014, 277-278, 44. 